\title{
Impact of Earth Greening on the Terrestrial Water Cycle $^{\mathscr{O}}$
}

\author{
Zhenzhong Zeng, ${ }^{\mathrm{a}}$ Shilong PiaO, ${ }^{\mathrm{a}, \mathrm{b}}$ LAURent Z. X. Li,${ }^{\mathrm{c}}$ TAO WANG,${ }^{\mathrm{b}}$ PhilipPe Ciais,, $\mathrm{a}$

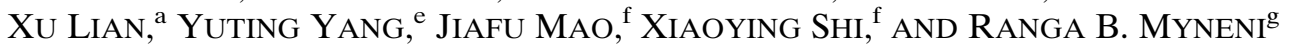 \\ ${ }^{a}$ Sino-French Institute for Earth System Science, College of Urban and Environmental Sciences, Peking \\ University, Beijing, China \\ ${ }^{\mathrm{b}}$ Institute of Tibetan Plateau Research, Chinese Academy of Sciences, Beijing, China \\ ${ }^{\mathrm{c}}$ Laboratoire de Météorologie Dynamique, CNRS, Sorbonne Université, UPMC Université Paris 06, Paris, France \\ ${ }^{\mathrm{d}}$ Laboratoire des Sciences du Climat et de l'Environnement, CEA-CNRS-UVSQ, Gif-sur-Yvette, France \\ ${ }^{\mathrm{e}}$ CSIRO Land and Water, Black Mountain, Canberra, Australian Capital Territory, Australia \\ ${ }^{\mathrm{f}}$ Environmental Sciences Division and Climate Change Science Institute, Oak Ridge National Laboratory, \\ Oak Ridge, Tennessee \\ ${ }^{\mathrm{g}}$ Department of Earth and Environment, Boston University, Boston, Massachusetts
}

(Manuscript received 11 April 2017, in final form 20 December 2017)

\begin{abstract}
Leaf area index (LAI) is increasing throughout the globe, implying Earth greening. Global modeling studies support this contention, yet satellite observations and model simulations have never been directly compared. Here, for the first time, a coupled land-climate model was used to quantify the potential impact of the satellite-observed Earth greening over the past 30 years on the terrestrial water cycle. The global LAI enhancement of $8 \%$ between the early 1980s and the early 2010s is modeled to have caused increases of $12.0 \pm$ $2.4 \mathrm{~mm} \mathrm{yr}^{-1}$ in evapotranspiration and $12.1 \pm 2.7 \mathrm{~mm} \mathrm{yr}^{-1}$ in precipitation-about $55 \% \pm 25 \%$ and $28 \% \pm$ $6 \%$ of the observed increases in land evapotranspiration and precipitation, respectively. In wet regions, the greening did not significantly decrease runoff and soil moisture because it intensified moisture recycling through a coincident increase of evapotranspiration and precipitation. But in dry regions, including the Sahel, west Asia, northern India, the western United States, and the Mediterranean coast, the greening was modeled to significantly decrease soil moisture through its coupling with the atmospheric water cycle. This modeled soil moisture response, however, might have biases resulting from the precipitation biases in the model. For example, the model dry bias might have underestimated the soil moisture response in the observed dry area (e.g., the Sahel and northern India) given that the modeled soil moisture is near the wilting point. Thus, an accurate representation of precipitation and its feedbacks in Earth system models is essential for simulations and predictions of how soil moisture responds to LAI changes, and therefore how the terrestrial water cycle responds to climate change.
\end{abstract}

\section{Introduction}

Thirty years of NOAA-AVHRR satellite measurements suggest that terrestrial foliar coverage has significantly increased over the period of satellite observation (Xu et al. 2013; Zhu et al. 2016); this finding is supported by model simulation results (Sitch et al. 2015), long-term forest inventories (Fang et al. 2014), and the observed enhanced seasonal exchange of $\mathrm{CO}_{2}$

Supplemental information related to this paper is available at the Journals Online website: https://doi.org/10.1175/ JCLI-D-17-0236.s1.

Corresponding author: Shilong Piao, slpiao@pku.edu.cn
(Forkel et al. 2016). Increased foliar coverage [leaf area index (LAI)] is expected to significantly influence the terrestrial water cycle. Ecosystem evapotranspiration (ET) generally increases with LAI (Jasechko et al. 2013; Zhang et al. 2015, 2016), which may accelerate the recycling of atmospheric moisture, and thus eventually affect precipitation $P$ (e.g., Spracklen et al. 2012). It should be noted that the response of $P$ to increasing LAI is complex (Sheil and Murdiyarso 2009) and involves not only the local sensitivity of $P$ to atmospheric moisture, but also shifts in atmospheric circulation and large-scale moisture convergence in some regions (Findell et al. 2011). Air masses exposed to higher LAI have been found to yield higher $P$ in tropical forests (Spracklen et al. 2012). In addition, changes in ET and $P$ driven by 
LAI also influence soil moisture, runoff, and the water yield of catchments (Ellison et al. 2012), where the change in soil moisture represents the change of background dryness over the region (e.g., Dai et al. 2004; Seneviratne 2012), and changes in runoff and water yield indicate the change of water amount produced by the region for other regions (e.g., Bosch and Hewlett 1982; Farley et al. 2005).

Compared with the impact of climate change on the recent Earth greening, our understanding of the climate impact of Earth greening is rather limited. Satellitederived LAI (Zhu et al. 2013, 2016) has increased significantly over all continents during the last 30 years, with an increase of $8 \%$ at a global scale from 1982 to 2011 (Figs. 1a,b and Figs. S1 and S2 in the online supplemental material). Our previous study (Zeng et al. 2017) addressed the impact of Earth greening on land surface air temperature, and this study focuses on its impact on the terrestrial water cycle. Recent observation-driven long-term global ET products (e.g., Jung et al. 2010; Zeng et al. 2014; Zhang et al. 2010, 2015, 2016) produced by offline diagnostic algorithms (land surface schemes that had not been coupled to climate models) have indicated that Earth greening has contributed to the increasing trend in global land ET over the last 30 years. However, the offline algorithm used to separate the contributions of each of the drivers in their studies cannot isolate the interactions among the drivers. In the observations, none of the driving factors can be considered in isolation given their strong interactions with each other. For example, an increase of $P$ is likely to increase ET, but the increase of $P$ itself could also be a result of increasing land ET and stronger recycling (Brubaker et al. 1993; Trenberth 1999; Bisselink and Dolman 2009; Dirmeyer et al. 2009). Further, these offline algorithms are incapable of investigating the response of the climate system (e.g., $P$, runoff, water yield, and soil moisture) to the greening-induced change in ET. The latter requires coupled model simulations.

In this study, we use a land-atmosphere coupled global climate model (GCM) to investigate the response of the terrestrial water cycle to the satellite-observed increase of LAI over the past 30 years, including changes in $P$, ET, soil moisture, runoff, and water yield. To exclude the large uncertainty in model simulations associated with the systematic sea surface temperature (SST) biases in fully coupled models (Kosaka and Xie 2013), we performed Atmospheric Model Intercomparison Project (AMIP) simulations to provide trustworthy decadal climate simulations (He and Soden 2016). We further applied a large initial condition ensemble (ICensemble; $n=50$ ) approach to reduce uncertainty around initial conditions (Kay et al. 2015; Sriver et al. 2015). We used the Institute Pierre Simon Laplace Coupled Earth System Model (IPSLCM, version 4; Dufresne et al. 2013), which was verified to have a sufficient capacity to reproduce the historical changes in temperature, $P$, and ET over land. Our study is novel for providing a first quantitative estimate of the impacts of the recent Earth greening (Zhu et al. 2016) on all hydrological components (e.g., ET, $P$, runoff, and soil moisture) with fully integrated process interactions and feedbacks.

\section{Materials and methods}

\section{a. Climate simulations}

The IPSLCM global climate model (Dufresne et al. 2013) from the Institute Pierre Simon Laplace (IPSL) modeling community was used in this study. It is one of the Earth system models used in phase 5 of the Coupled Model Intercomparison Project (CMIP5; Taylor et al. 2012) for the Intergovernmental Panel on Climate Change (IPCC) Fifth Assessment Report (IPCC 2013). The atmospheric model is the Laboratoire de Météorologie Dynamique zoom model (LMDZ; Li 1999; Hourdin et al. 2006), and the land surface model is Organizing Carbon and Hydrology in Dynamic Ecosystems (ORCHIDEE; Krinner et al. 2005). The latter was modified to replace LAI at each grid point and for each plant functional type (PFT) separately, with satellite-observed values. This aggregation was performed using the native fine resolution of the satellite LAI and land-cover data $(\sim 1 \mathrm{~km})$ for averaging to the model grid. Thirteen PFTs are used to describe the vegetation cover: bare soil, two tropical forests, three temperate forests, three boreal forests, two grasslands, and two agricultural ecosystem types. The model has been well tested against observations and with proven capacity in simulating evapotranspiration (Mueller and Seneviratne 2014; Traore et al. 2014) and soil moisture (Rebel et al. 2012).

To document the transient response of the terrestrial water cycle to the satellite-observed LAI for the past 30 years, we conducted two 30-yr-long standard simulations following the protocol defined in the AMIP. Both simulations are constrained by realistic sea surface temperature and sea ice from 1982 to 2011, but one is run with monthly varying climatological (1982-2011) LAI maps, that is, without any year-to-year variation (AMIP_STD) and the other is constrained with the monthly LAI maps from 1982 to 2011 (AMIP_LAI). The difference between the two model runs (AMIP LAI - AMIP_STD) isolates the LAI-induced changes in the terrestrial water cycle. The response of model behavior to a boundary perturbation (i.e., LAI at the land surface in this study) is a problem for the 


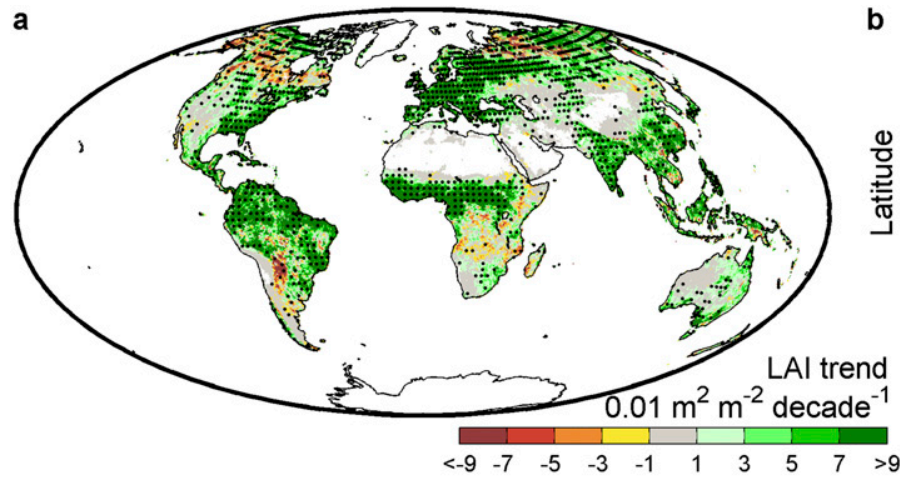

C

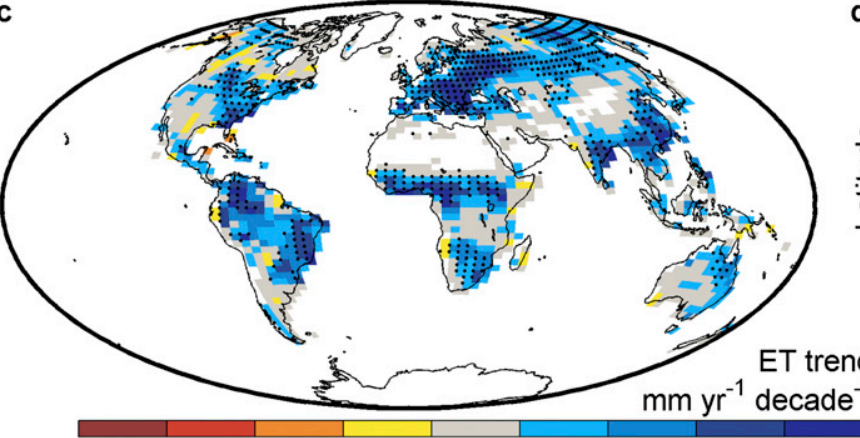

ET trend

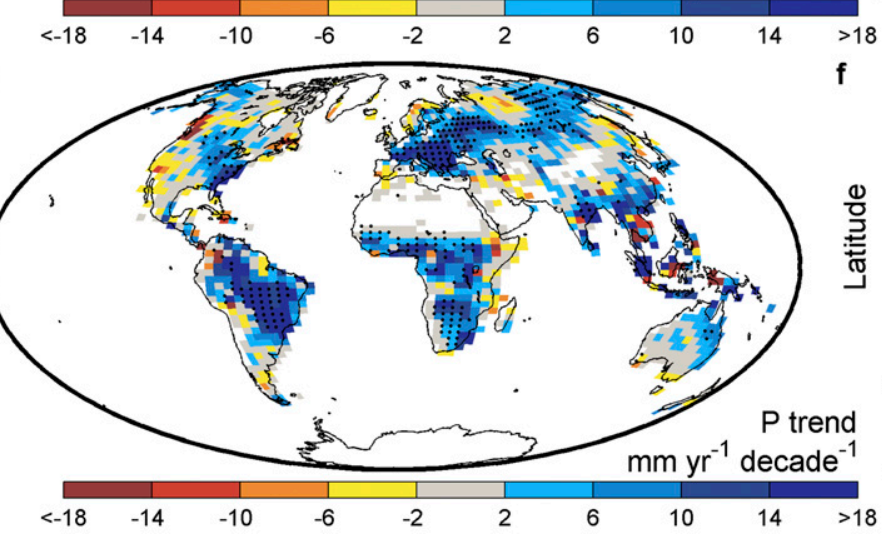

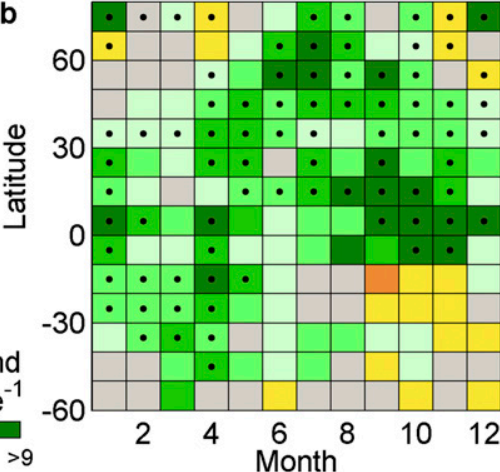

d
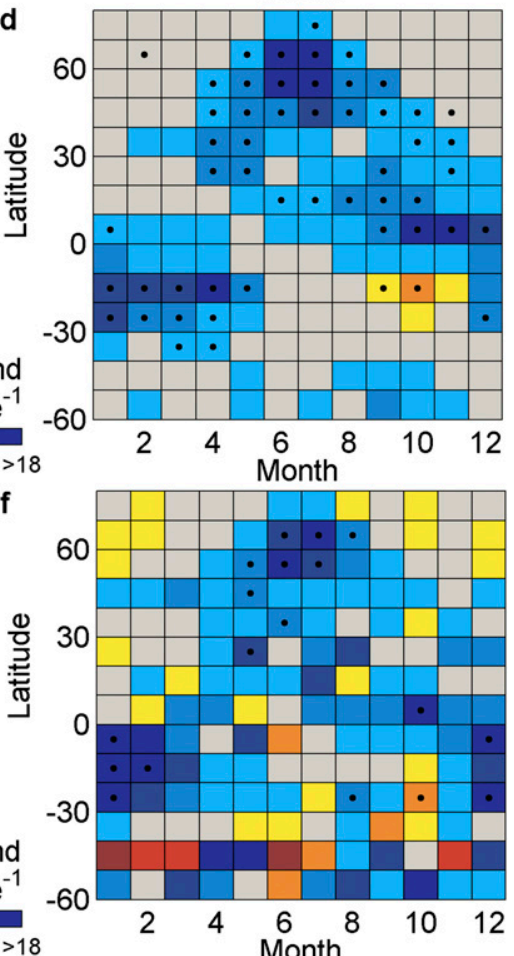

FIG. 1. LAI trends and the LAI-induced trends in ET and $P$. (a) Spatial patterns of the LAI trend for 1982-2011 and (b) the LAI trend in latitude-month space. Spatial patterns of the LAI-induced (c) trend in annual ET, (d) the ET trend in latitude-month space, (e) the trend in annual $P$, and (f) the $P$ trend in latitude-month space. LAIinduced variations of ET and $P$ are isolated from AMIP_LAI - AMIP_STD. Dots indicate a significant trend for 1982-2011 $(p<0.05)$

predictability of the second kind, and it is strongly influenced by initial conditions, which the atmosphere, as a chaotic system, has a high sensitivity to (Lorenz 1963). Here, to reduce the uncertainty resulting from initial conditions, both the simulations were repeated 50 times with different initial conditions (IC-ensemble), and the average of the ensemble members was analyzed. The initial conditions were derived from the model output of an unperturbed 80-yr run forced with the 1982 LAI distribution-the first 30 years of the run for the spinup of the model (thus the simulated soil moisture was in balance with the observed
LAI-constrained climate), and the last 50 years of the run for the initial conditions. Figure 2 shows that a 50member ensemble is large enough to allow us to neglect the uncertainty from initial conditions. These 50member ensembles of transient simulations, including 36960 simulation months, need intensive computational resources. All the transient simulations, with a resolution of $2.5^{\circ}$ latitude $\times 3.75^{\circ}$ longitude, 19 vertical levels, and a 1.5-min time step, were run at the Institut du Développement et des Ressources en Informatique Scientifique/ Centre National de la Recherche Scientifique (IDRIS/ CNRS), France. 


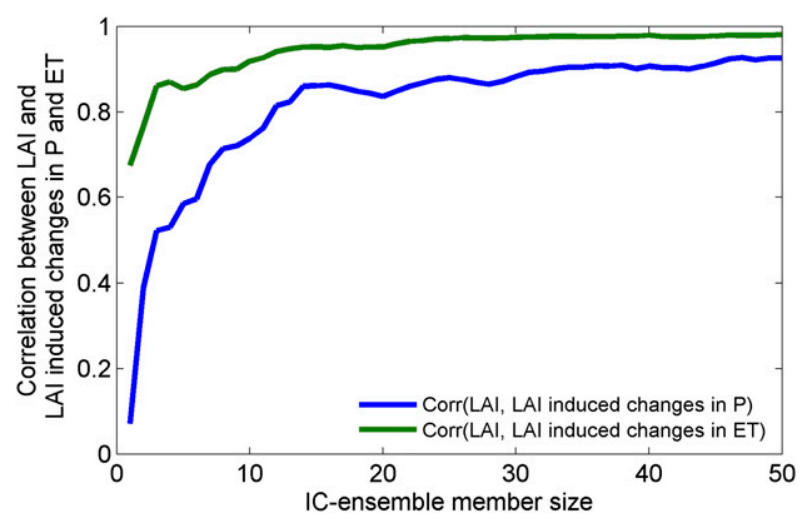

FIG. 2. Plot of the correlation between LAI and LAI-induced variations in land $P$ (blue line) and ET (green line) vs IC-ensemble member size.

The main simulations (AMIP_LAI and AMIP_STD) have constant radiative forcings. To address whether the effects of rising atmospheric $\mathrm{CO}_{2}$ change the climate feedback of increasing LAI, we further performed four equilibrium simulations investigating the equilibrium response of the climate system to increasing LAI. Four 60-yr-long simulations that share the same setup were forced by different seasonal LAI maps and different atmospheric $\mathrm{CO}_{2}$ concentrations: one control run (CTL) with LAI prescribed as the average observed from 1982 to 1986 and $\mathrm{CO}_{2}$ held at 341 parts per million (ppm; the level of atmospheric $\mathrm{CO}_{2}$ concentration in 1982); two partial-perturbation runs-transient run (TRN) with LAI set as in CTL but $\mathrm{CO}_{2}$ at $391 \mathrm{ppm}$ (the level in 2011), and transient run for LAI (TLI) with $\mathrm{CO}_{2}$ set as in CTL but LAI as the average observed from 2007 to 2011; and another total-perturbation run [recent run (REC), with both perturbations in $\mathrm{CO}_{2}$ and LAI] simulating the recent past with LAI as the average observed from 2007 to 2011 and $\mathrm{CO}_{2}$ at $391 \mathrm{ppm}$. The equilibrium response of the terrestrial water cycle is isolated from the comparison between REC and TRN. ET change between TLI and CTL shows the sensitivity of ET to LAI when $\mathrm{CO}_{2}$ was held at the level of 1982, and that between REC and TRN shows the sensitivity when $\mathrm{CO}_{2}$ was held at the level of 2011. Thus, the difference between REC - TRN and TLI - CTL could be used to test whether the effects of rising $\mathrm{CO}_{2}$ change the sensitivity of ET to LAI during the past 30 years. The first 10 years of the simulations were excluded from the analysis to ensure soil moisture fields were in equilibrium with climate. The analysis was thus performed on the last 50 years of the simulations. The long averaging period allows us to quantify unforced internal climate variability for analyzing the mean effect of LAI differences on climate. For this experiment, the model was run on the Tianhe supercomputer (TH-1A) in China, and the model resolution was $1.5^{\circ}$ latitude $\times 3.0^{\circ}$ longitude, with 19 vertical levels and a 1.5 -min time step.

For both the transient and equilibrium experiments, LAI was prescribed for each grid point and for each PFT from the AVHRR 8-km global LAI product (Zhu et al. 2013). The solar constant is $1368 \mathrm{~W} \mathrm{~m}^{-2}$. Other greenhouse gases and aerosols were kept constant in the transient experiments to better focus on the land surface effects [e.g., $\mathrm{CH}_{4}$ is 1650 parts per billion (ppb), $\mathrm{N}_{2} \mathrm{O}$ is $306 \mathrm{ppb}, \mathrm{CFC}_{11}$ is 280 parts per trillion (ppt), and $\mathrm{CFC}_{12}$ is $484 \mathrm{ppt}] . \mathrm{CO}_{2}$ in the transient experiments has been set to $341 \mathrm{ppm}$ (1982's level). The effects of rising atmospheric $\mathrm{CO}_{2}$ on the climate feedback of increasing LAI were characterized by the equilibrium experiments. Pixels with a multiyear (1982-2011) average LAI $<0.1$ were excluded from the analysis. In the equilibrium experiment, the monthly sea surface temperature and sea ice were set from seasonal climatology (1982-2011) so that the results focus on the land surface effects (Bounoua et al. 2000; Hales et al. 2004).

\section{b. Observation-based datasets}

Long-term forest inventories (McMahon et al. 2010; Fang et al. 2014), ecosystem model simulation results (Mahowald et al. 2016; Sitch et al. 2015), and the observed enhanced seasonal exchange of $\mathrm{CO}_{2}$ in the Northern Hemisphere (Graven et al. 2013; Forkel et al. 2016) are consistent with the evidence of a greening of Earth during the last 30 years. To quantify the greening, the long-term NOAA-AVHRR satellite measurements offer an unprecedented dataset because they are the only ones covering the last 35 years. Here, the Earth greening in IPSLCM GCM is constrained by the longterm global satellite dataset of LAI3g, an 8-km global LAI product from 1982 to 2011 derived from the NOAA-AVHRR satellite measurements (Zhu et al. 2013). It was produced by a set of neural networks trained on best-quality and significantly postprocessed MODIS LAI and AVHRR Global Inventory Modeling and Mapping Studies (GIMMS) NDVI3g data for the overlapping period between the two sensors (Zhu et al. 2013). This satellite LAI product has been extensively evaluated against field measurements, validated as a research-quality dataset, and used in numerous previous studies to understand trends in the terrestrial carbon and water exchange (Zhu et al. 2013, 2016; Pfeifer et al. 2014; Zeng et al. 2017).

The monthly LAI from LAI3g was applied to force IPSLCM GCM in the transient experiment. In addition, we extracted the multiyear average annual cycle of global land LAI during the early 1980s (1982-86) and the early 2010s (2007-11) to be used in the equilibrium 


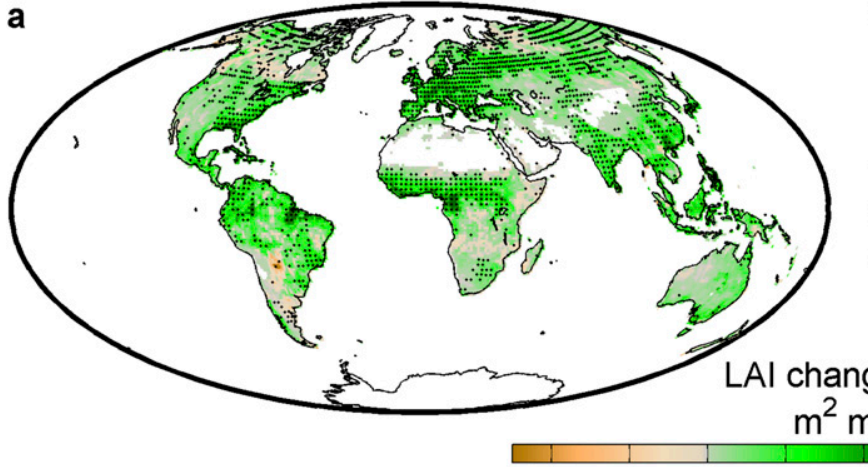

$\begin{array}{lllll}-0.4 & -0.2 & 0 & 0.2 & 0.4\end{array}$

C

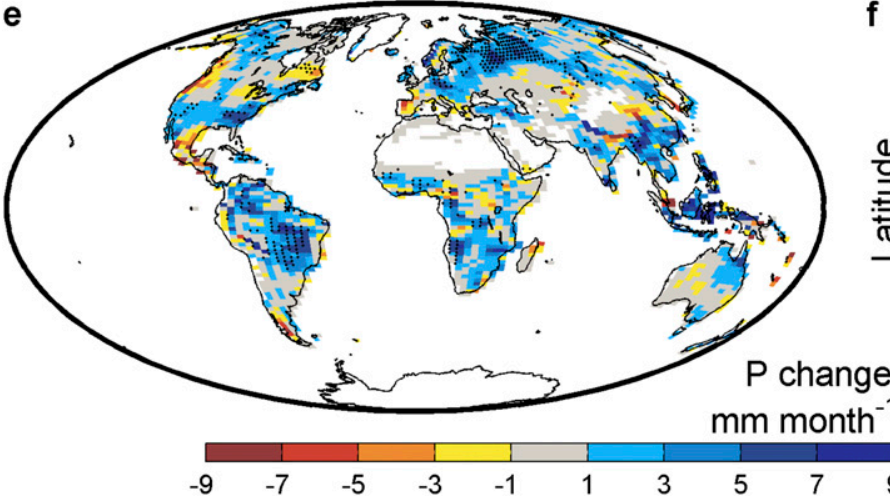

ET change

b 90

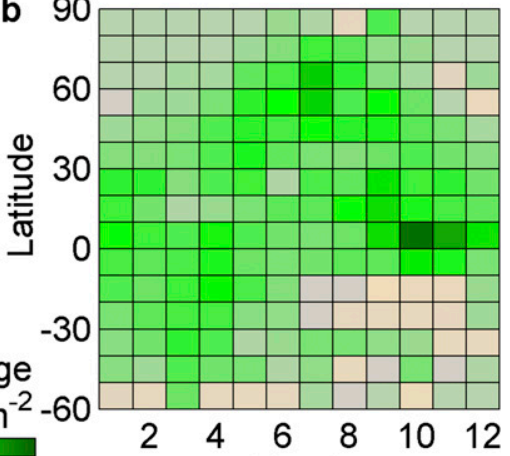

Month

d 90
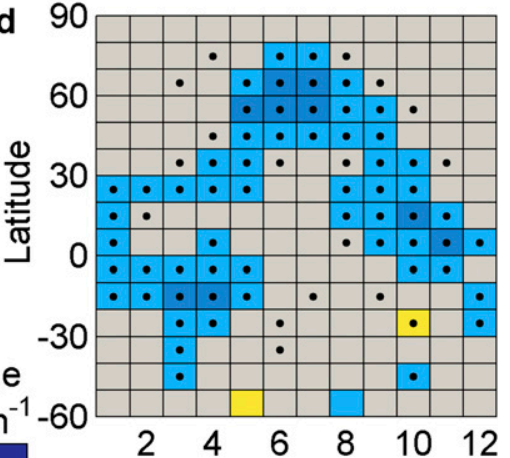
$\mathrm{mm}$ month $^{-1}-60$ $\begin{array}{llllll}2 & 4 & 6 & 8 & 10 & 12\end{array}$ Month

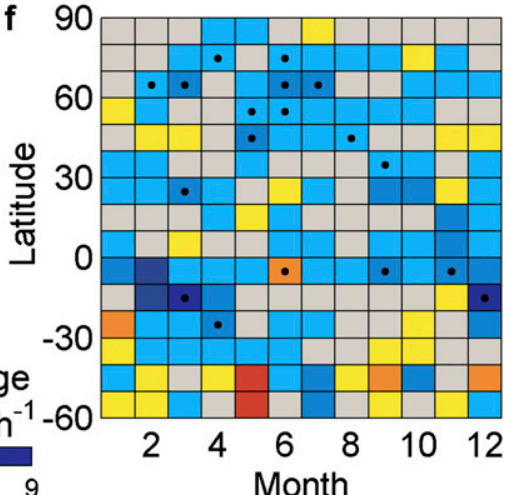

FIG. 3. Patterns of the (top) enhanced LAI, (middle) induced ET change, and (bottom) $P$ change using the equilibrium experiment (REC - TRN). (a) Spatial patterns of the LAI change between the early 1980s (1982-86) and the early 2010s (2007-11) and (b) the LAI change in latitude-month space. Spatial patterns of the enhanced LAI-induced (c) change in annual ET, (d) the ET change in latitude-month space, (e) change in annual $P$, and (f) the $P$ change in latitude-month space. Dots indicate a significant difference in the simulations between REC and TRN based on a two-sample $t$ test $(p<0.05, n=50)$.

experiment. The two periods represent enhanced LAI at a global scale, although a few regions do show a decrease of LAI (Figs. 1a,b and 3a,b). The AMIP provides observed monthly maps of sea surface temperature and sea ice from 1982 to 2011 for use in the simulations.

Several observation-based datasets have been constructed and applied to detect variations of the terrestrial water cycle during the past three decades. The five long-term global land ET products used in this study are the Flux Network model tree ensemble (FLUXNETMTE) ET, based on eddy covariance measurements (Jung et al. 2010); the Gravity Recovery and Climate Experiment model tree ensemble (GRACE-MTE) ET, which in addition used the satellite-observed water mass balance (Zeng et al. 2014); the remote sensing products of modified Penman-Monteith (MPM) ET (Zhang et al. 2010); Process-Based Land Surface Evapotranspiration/ Heat Fluxes (P-LSH) ET (Zhang et al. 2015); and 
Penman-Monteith-Leuning (PML) ET (Zhang et al. 2016). All these datasets used vegetation remote sensing and climate fields as drivers in their algorithms to reconstruct the interannual variability of global land ET over the last 30 years (Table S1). Because of the lack of direct observations, it is difficult to estimate the biases in these products derived from errors in both drivers and algorithms. Thus we included the five datasets in this study to define an uncertainty range in the observed land ET. The two global precipitation datasets for the period 1982-2011 are from observations assembled in the Climatic Research Unit (CRU) time series, version 3.21 (Harris et al. 2014), and the Global Precipitation Climatology Centre Full Data Reanalysis, version 6 (GPCC; Schneider et al. 2011). The global near-surface air temperatures and potential evapotranspiration for 1982-2011 are also derived from the CRU dataset, which is grounded on analysis of more than 4000 individual meteorological station records (Harris et al. 2014).

\section{Results}

\section{a. Model performance}

The LMDZ climate model and ORCHIDEE land surface model are both largely used state-of-the-art models in the climate community and have been well tested against observations. Here, we retested the capacity of the model to simulate the global climate using the observation-based reconstructions of near-surface air temperature, precipitation, and evapotranspiration from 1982 to 2011. Among all the simulations above, the one closest to the historical climate is the IC-ensemble of simulations constrained by realistic sea surface temperature and sea ice and LAI for 1982-2011 (AMIP LAI). The model is evaluated by a comparison between the observation-based reconstructions and this ICensemble of AMIP_LAI. We found that the modeled temperature is significantly and highly correlated with the observed surface air temperature at both spatial distribution $(R=0.99, p<0.01$; Fig. S3d $)$ and temporal variation $(R=0.84, p<0.01$; Fig. S3e). Figures S4 and S5 also show that the model has good capacity in reproducing global land precipitation (spatial correlation: $R=0.70, p<0.01$; temporal correlation: $R=0.82, p<$ 0.01 ), and global land evapotranspiration (spatial correlation: $R=0.84, p<0.01$; temporal correlation: $R=$ $0.89, p<0.01)$, respectively.

Because ET is a nexus in the feedback of land greening to the terrestrial water cycle (e.g., Shukla and Mintz 1982; Sheil and Murdiyarso 2009; Spracklen et al. 2012; Swann et al. 2012; Makarieva et al. 2013), we also evaluate the modeled sensitivity of ET to LAI using three satellite-derived reconstructions of long-term land ET (FLUXNET-MTE ET, GRACE-MTE ET, and MPM ET). In our transient experiment, the sensitivity of land ET to LAI ( $\partial \mathrm{ET} / \partial \mathrm{LAI})$ is calculated from the regression $\delta \mathrm{ET}=k_{1} \mathrm{LAI}+c_{1}$, where $\mathrm{LAI}$ is the global average annual LAI from 1982 to $2011, \delta$ ET is the LAIinduced change in annual land ET (AMIP_LAI AMIP_STD) from 1982 to 2011, and $k_{1}$ is the modeled sensitivity of land ET to LAI. The same approach is also applied to estimate the observed sensitivity of land ET to LAI using the long-term observations of LAI and ET: $\mathrm{ET}=k_{2} \mathrm{LAI}+c_{2}$, where $\mathrm{ET}$ is the global average annual land ET from 1982 to 2011 from several observationbased estimates (FLUXNET-MTE, GRACE-MTE, MPM, and the ensemble of these observations), and $k_{2}$ is the estimated observed sensitivity of land ET to LAI. As the observed land ET is also strongly affected by other factors, we need to estimate the observed sensitivity by statistically controlling precipitation and temperature: $\mathrm{ET}=k_{3} \mathrm{LAI}+c_{3} P+c_{4} T_{a}+c_{5}$, where $P$ and $T_{a}$ are the observed annual land precipitation and surface air temperature during 1982-2011 from the CRU dataset, respectively, and $k_{3}$ is the estimated observed sensitivity of land ET to LAI, statistically controlling $P$ and $T_{a}$. The modeled sensitivity of land ET to LAI is $0.92 \pm 0.03 \mathrm{~mm} \mathrm{yr}^{-1}$ decade $^{-1}$ per $0.01 \mathrm{~m}^{2} \mathrm{~m}^{-2}$ decade $^{-1}$ $(p<0.01)$, which is nearly the same as the optimal estimate of observed sensitivity $\left(0.96 \pm 0.13 \mathrm{~mm} \mathrm{yr}^{-1}\right.$ per $0.01 \mathrm{~m}^{2} \mathrm{~m}^{-2}, p<0.01$; the ensemble of observed $\partial \mathrm{ET} / \partial \mathrm{LAI}$ statistically controlling precipitation and temperature; Fig. 4a). Furthermore, the modeled sensitivities of land ET to LAI at all latitudes are within the ranges of the sensitivities from the satellite-derived observations (Fig. 4).

We noticed that the modeled $\partial \mathrm{ET} / \partial \mathrm{LAI}$ in our IPSLCM simulations differs from the modeled $\partial E T / \partial L A I$ in the IPSLCM simulations for CMIP5 (Zeng et al. 2016), which could be attributed to the following two factors. First, because $\partial \mathrm{ET} / \partial \mathrm{LAI}$ is physically influenced by the magnitude of LAI (Zeng et al. 2016), prescribing the observed LAI into the model should automatically adjust the sensitivity to an extent. Second, more importantly, $\partial \mathrm{ET} / \partial \mathrm{LAI}$ varied a lot even for the same model with different resolutions and physical schemes. For example, using the temporal variations of ET and LAI from CMIP5 simulations, Zeng et al. (2016) found that $\partial \mathrm{ET} / \partial \mathrm{LAI}$ is $4.98 \pm 0.85 \mathrm{~mm} \mathrm{yr}^{-1}$ per $0.01 \mathrm{~m}^{2} \mathrm{~m}^{-2}(p<0.01)$ in IPSL-CM5A-LR, $3.50 \pm$ $0.78 \mathrm{~mm} \mathrm{yr}^{-1}$ per $0.01 \mathrm{~m}^{2} \mathrm{~m}^{-2}(p<0.01)$ in IPSLCM5A-MR, and $1.51 \pm 0.57 \mathrm{~mm} \mathrm{yr}^{-1}$ per $0.01 \mathrm{~m}^{2} \mathrm{~m}^{-2}$ $(p<0.01)$ in IPSL-CM5B-LR. The climate model used in this study is IPSLCM, version 4 , with a resolution of 

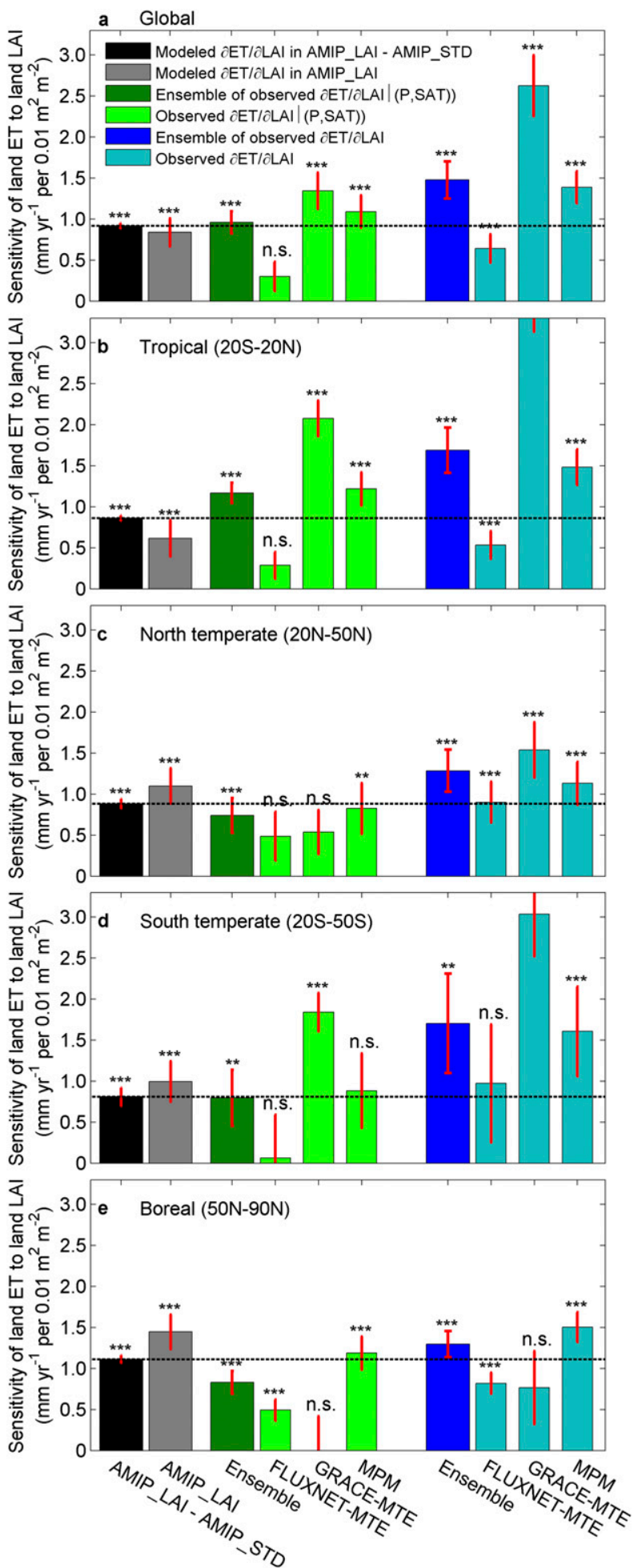

FIG. 4. Sensitivities of land ET to LAI from the IPSLCM model (black bar: AMIP_LAI - AMIP_STD; gray bar: AMIP_LAI), the observations using simple regression (blue bars), and the observations using multiple regressions controlling $P$ and surface air temperature (green bars) for (a) global, (b) tropical, (c) north temperate, (d) south temperate, and (e) boreal latitude bands. $2.5^{\circ}$ latitude $\times 3.75^{\circ}$ longitude, 19 vertical levels, and a 1.5-min time step. Using the same approach as in Zeng et al. (2016) and calculated with the temporal variations of ET and LAI from AMIP_LAI simulations, $\partial \mathrm{ET} / \partial \mathrm{LAI}$ was $0.84 \pm 0.17 \mathrm{~mm} \mathrm{yr}^{-1}$ per $0.01 \mathrm{~m}^{2} \mathrm{~m}^{-2}$ $(p<0.01)$, which is similar to the estimate from AMIP LAI - AMIP_STD and within the range of the estimates from the observations using the same approach (Fig. 4). Zeng et al. (2017) found that accurate representation of the ratio of transpiration to total evapotranspiration is the key reason why the IPSLCM model used in this study accurately simulates the response of ET to LAI change.

\section{b. Effects of $\triangle L A I$ on the terrestrial water cycle}

The enhancement of LAI (greening) during the last 30 years (Figs. 1a,b) leads to a pronounced increase of ET (Figs. 1c,d) and $P$ (Figs. 1e,f) over the globe. Spatially, the trend in ET $(\Delta \mathrm{ET}$, defined as $\partial \delta \mathrm{ET} / \partial t$ where $\delta \mathrm{ET}$ is the LAI-induced change in annual ET from AMIP LAI - AMIP_STD) rises with the change in LAI ( $\Delta \mathrm{LAI}$, defined as $\partial \mathrm{LAI} / \partial t$ ), defining an average sensitivity of $1.0 \mathrm{~mm} \mathrm{yr}^{-1}$ decade $^{-1}$ per $0.01 \mathrm{~m}^{2} \mathrm{~m}^{-2}$ decade $^{-1}$ increase in LAI $\left(R^{2}=0.58, p<0.01\right.$; Fig. S6a $)$. The patterns of $\Delta P$ are not identical to those of $\Delta \mathrm{LAI}$ everywhere (cf. Figs. 1e,f and 1a,b). The $\Delta$ LAI can only explain $14 \%$ of the spatial variation in $\Delta P$ (Fig. S6b), which is about half of the fraction of $\Delta P$ explained by $\Delta$ ET (Fig. S6c). The results indicate that $\Delta$ LAI-induced changes in the terrestrial water cycle are derived from, and dominated by, an influence on ET. On the one hand, $\Delta$ ET changes the amount of atmospheric precipitable water, causing $\Delta P$, with the spatial distribution of $\Delta P$ influenced by the atmospheric circulation (Spracklen et al. 2012; Swann et al. 2012; Devaraju et al. 2015); on the other hand, $\Delta \mathrm{ET}$ also changes land surface air temperature and atmospheric circulation (Zeng et al. 2017), which may change moisture convergence and regulate both the magnitude and the spatial distribution of $\Delta P$ (Findell et al. 2011).

We analyzed the effects of $\Delta \mathrm{LAI}$ on global and continental water budgets (Fig. 5). Globally, increasing LAI amplifies both land ET and land $P$ (Figs. 5a and 6). The

Ensemble sensitivity is calculated with the average of the observations. The horizontal dashed line is the modeled sensitivity. Error bars show one standard error of the sensitivity. The significance of sensitivity is shown with asterisks, where $* * *$ indicates significance at the $99 \%$ confidence interval, $* *$ indicates significance at the $95 \%$ confidence interval, * indicates significance at the $90 \%$ confidence interval, and n.s. means not significant. 

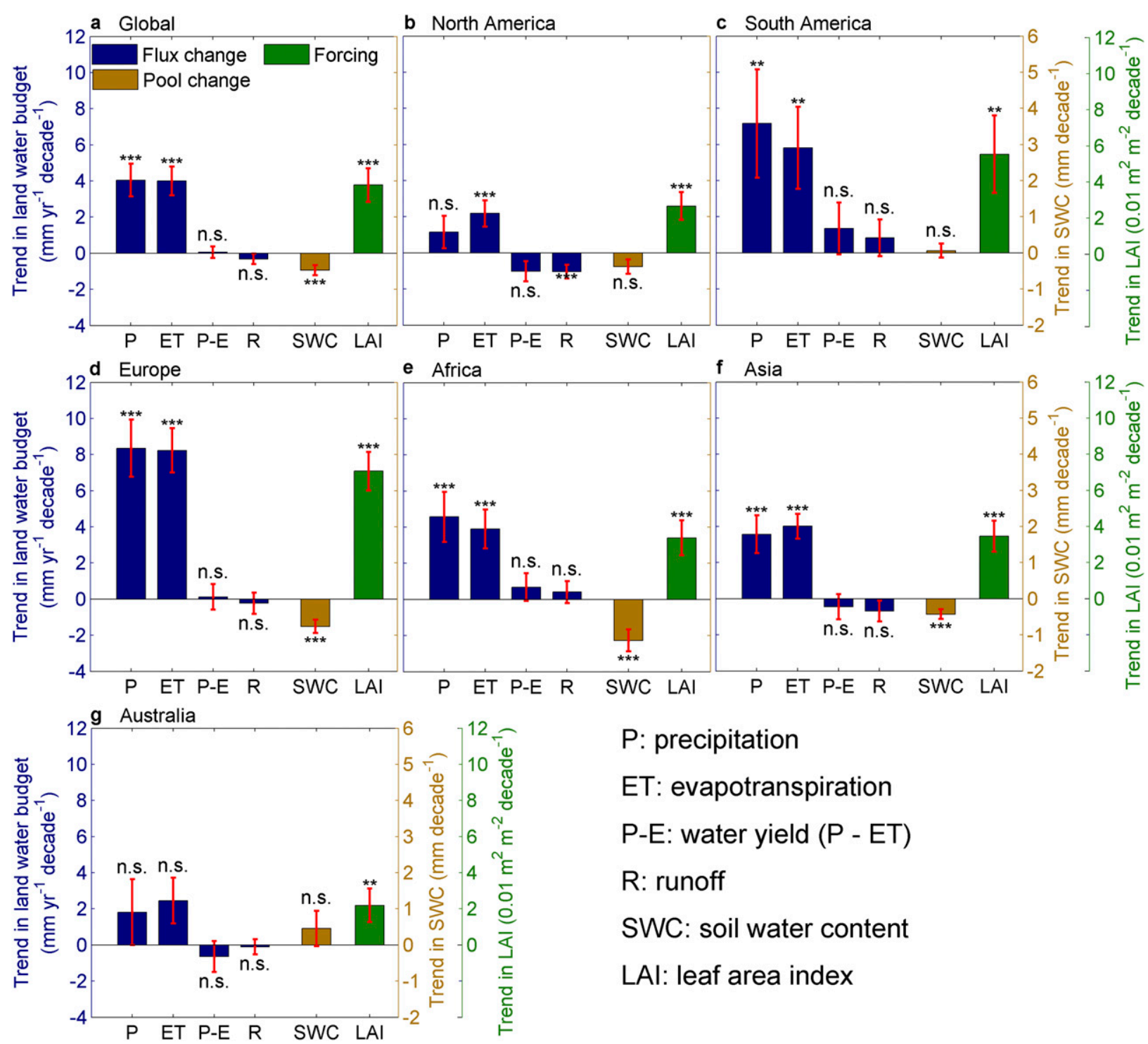

P: precipitation

ET: evapotranspiration

P-E: water yield (P - ET)

R: runoff

SWC: soil water content

LAl: leaf area index

FIG. 5. Effects of the increasing LAI on global and continental water budgets. The increasing LAI-induced trends in the terrestrial water budget from AMIP_LAI - AMIP_STD on (a) global and (b)-(g) continental scales. Error bars show the standard error of the trends; $* * *$ indicates significant trends at the $99 \%$ confidence interval, $* *$ indicates significance at the $95 \%$ confidence interval, and n.s. means not significant.

$\Delta$ ET and $\Delta P$ are $4.0 \pm 0.8 \mathrm{~mm} \mathrm{yr}^{-1}$ decade $^{-1}$ (mean \pm 1 standard error, $p<0.01)$, and $4.0 \pm 0.9 \mathrm{~mm} \mathrm{yr}^{-1}$ deca$\mathrm{de}^{-1}(p<0.01)$, respectively. Although an increase of ET is likely to result in a reduction of local runoff $R$ and water yield $(P-E$, defined as the difference between $P$ and ET; e.g., Jackson et al. 2005; Goulden and Bales 2014), our results indicate that the global $\Delta R$ and $\Delta P-E$ caused by $\Delta$ LAI are not significant ( $p>0.05$; Fig. 5a). Because local $\Delta$ ET also amplifies $P$ downwind, the loss of local runoff and $P-E$ is partly offset by positive $\Delta P$ in nearby regions; the degree to which this occurs will be influenced by the atmospheric circulation (van der Ent and Savenije 2011; Spracklen et al. 2012; Swann et al.
2012; Devaraju et al. 2015) and thus is scale-dependent (Fig. S7). At the continental scale, the proportion of the $\Delta$ LAI-induced ET that precipitates on the ocean (van der Ent et al. 2010) may have been offset by an increase of ocean-land water transport (Table 1), resulting from changes in atmospheric circulation (Zeng et al. 2017). Additionally, although $\Delta \mathrm{LAI}$-induced change in global soil water content (SWC) is statistically significant ( $p<0.01$; Fig. 5a), its magnitude is only $-0.5 \pm$ $0.1 \mathrm{~mm} \mathrm{decade}^{-1}$, tentatively suggesting a weak impact of Earth greening on soil moisture at a global scale.

Enhanced LAI significantly increases ET over nearly all the continents $(p<0.05$; Figs. 5b-f), except for 


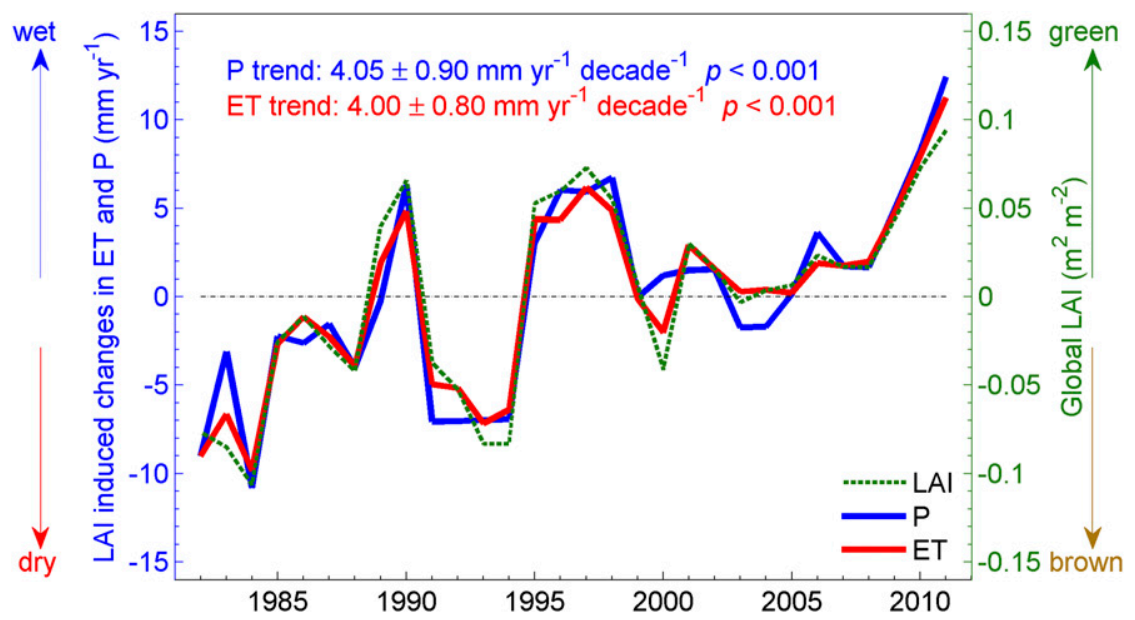

FIG. 6. Temporal variations of global average LAI (green line) and LAI-induced variations in land ET (red line) and land $P$ (blue line). LAI-induced variations of ET and $P$ are isolated from AMIP_ LAI - AMIP_STD. Inserted numbers show the trend of LAI-induced variation of ET and $P$.

Australia, where $\Delta \mathrm{ET}$ is not significant, despite a locally positive change of LAI ( $p>0.05$; Fig. $5 \mathrm{~g})$. The impact of $\Delta$ LAI on regional precipitation is more heterogeneous. The $\Delta P$ is positive, although less than $\Delta \mathrm{ET}$, over North America, Asia, and Australia (Figs. 5b,f,g), and nearly equal to $\Delta$ ET over Europe (Fig. 5d). For South America and Africa, both $\Delta P$ and $\Delta \mathrm{ET}$ are positive, but $P$ increases more than ET in response to $\Delta$ LAI (Figs. $5 \mathrm{c}, \mathrm{e}$ ). As a result, continental runoff and $P-E$ increase over South America and Africa, but slightly decrease over North America, Asia, and Australia (Figs. 5b-g). In addition, the decrease of SWC caused by the greening of Earth is also weak at the continental scale (Figs. 5b-g). Thus, the terrestrial water cycle has been intensified by recent Earth greening; on both global and continental scales, enhanced LAI accelerates the turnover of soil moisture through a coincident increase of ET and $P$ and does not meaningfully decrease runoff, $P-E$, and SWC (Figs. 5b-g and Fig. S8). Additionally, the equilibrium response of the terrestrial water cycle to the change in LAI (Fig. 3 and Fig. S9) is similar to the transient response (Figs. 1 and 2), with greater similarity in the ET response than in the $P$ response.
The effect of $\triangle \mathrm{LAI}$ on SWC over the globe is weak, since positive soil moisture trends at some locales have been largely canceled out by negative trends at others. There is an intensive reduction of SWC in many dry regions, for example, in the Sahel, west Asia, northern India, the western United States, and the Mediterranean coast (Fig. 7a and Fig. S10). In the western United States, the decrease in SWC is likely caused by the decrease in local $P$ (Fig. 1e); the latter could be a result of the greening-induced circulation change. In the Sahel, west Asia, and the Mediterranean coast, as the greening significantly increased local $P$ (Fig. 1e), the cause for SWC change is not $P$ but ET. In these regions, because the correlation between $\triangle \mathrm{ET}$ and $\triangle$ SWC has shifted from nonsignificant in the beginning years to significant and negative in recent years (Fig. 8), the reduction in soil moisture (SM) could further suppress ET and cease the $\Delta \mathrm{LAI}$-induced increase of $P$. Soil moisture becoming limited explains why the observed greening does not increase ET in some dry regions (e.g., northern India, Figs. 1c and 7a). The greening-induced intensification of the terrestrial water cycle is therefore subject to a progressive emergence of constraints by limited moisture supply in dry regions (Fig. S11).

TABLE 1 . Trends of land precipitation $P_{L}$, land evapotranspiration $E_{L}$, and ocean-land water transport $E_{O}-P_{O}$ in the AMIP_STD, AMIP_LAI ensemble simulations. Uncertainty is the standard error of the trend.

\begin{tabular}{lccc}
\hline \hline & $P_{L}\left(\mathrm{~mm} \mathrm{yr}^{-1} \mathrm{decade}^{-1}\right)$ & $E_{L}\left(\mathrm{~mm} \mathrm{yr}^{-1} \mathrm{decade}^{-1}\right)$ & $E_{O}-P_{O}\left(\mathrm{~km}^{3} \mathrm{yr}^{-1} \mathrm{decade}^{-1}\right)$ \\
\hline AMIP_STD & $9.9 \pm 4.3^{\mathrm{a}}$ & $3.5 \pm 0.9^{\mathrm{b}}$ & $962 \pm 504^{\mathrm{c}}$ \\
AMIP_LAI & $14.0 \pm 4.5^{\mathrm{b}}$ & $7.5 \pm 1.4^{\mathrm{b}}$ & $969 \pm 516^{\mathrm{c}}$ \\
AMIP_LAI - AMIP_STD & $4.0 \pm 0.9^{\mathrm{b}}$ & $4.0 \pm 0.8^{\mathrm{b}}$ & $7 \pm 51$
\end{tabular}

\footnotetext{
${ }^{\text {a }}$ Significance at $p<0.05$.

b Significance at $p<0.01$.

${ }^{\mathrm{c}}$ Significance at $p<0.1$.
} 

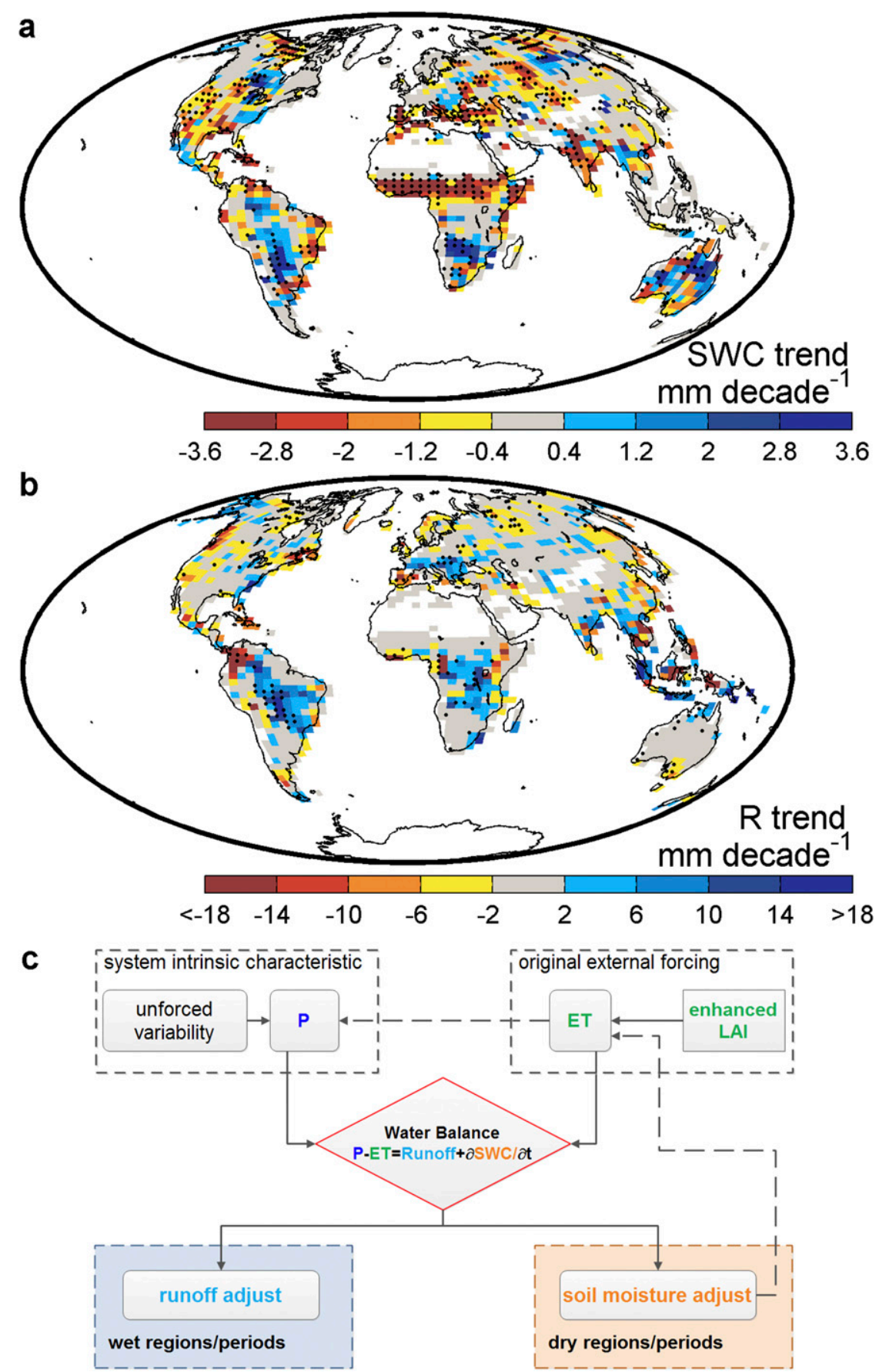

FIG. 7. Response of SWC and runoff to increasing LAI. (a) Spatial pattern of the LAIinduced trend in SWC. (b) Spatial pattern of the LAI-induced trend in runoff. (c) Schematic of the different responses of the terrestrial water cycle to the enhanced LAI over wet/dry regions. Dots indicate a significant trend for 1982-2011 $(p<0.05)$.

\section{c. Mechanisms of $\Delta L A I$-induced terrestrial water cycle change}

The satellite-observed increase of LAI by $8 \%$ from 1982 to 2011 is modeled to result in a relative increase of plant transpiration by $5 \%$. In magnitude, ET from vegetation dominated by transpiration (Jasechko et al. 2013) increases by $6.4 \pm 1.3 \mathrm{~mm} \mathrm{yr}^{-1}$ decade $^{-1}(p<0.01$, Fig. 9a). As the increase of transpiration consumes more water and energy, soil evaporation decreases 


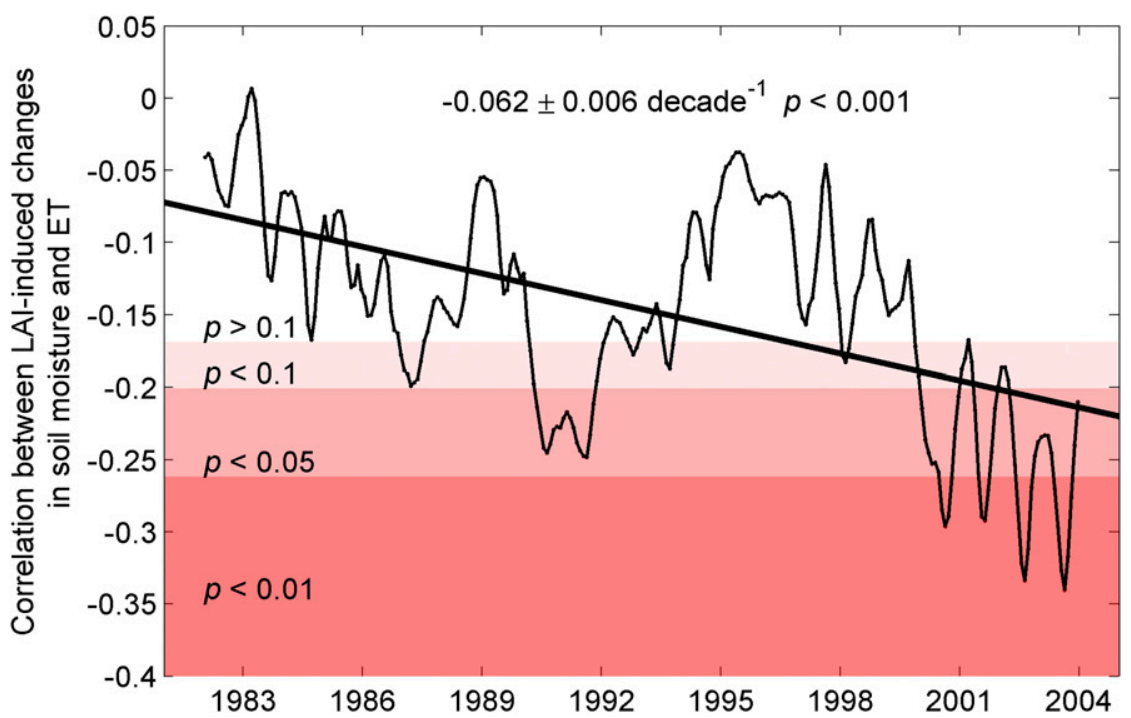

FIG. 8. Correlation coefficient between LAI-induced changes in soil moisture and ET over dry regions with aridity index $>2\left(R_{\Delta \mathrm{ET}, \Delta \mathrm{SM}}\right)$ against time; $R_{\Delta \mathrm{ET}, \Delta \mathrm{SM}}$ is calculated with the $\Delta$ LAI-induced changes in SM and ET in each moving window of 96 months ( 8 years). The $x$ axis shows the beginning time of the moving window. Background colors indicate the significance level of the correlation $(p<0.01$, indicates a significant correlation at the $99 \%$ confidence interval; $p<0.05$, at the $95 \%$ confidence interval; $p<0.1$, at the $90 \%$ confidence interval; and $p>0.1$, no significance).

by $-2.3 \pm 0.5 \mathrm{~mm} \mathrm{yr}^{-1}$ decade $^{-1}(p<0.01$, Fig. $9 b)$. Such an opposing response of transpiration and evaporation to increasing LAI is independently corroborated by results of offline diagnostic ET algorithms driven by observations (Zhang et al. 2016). As a net effect, the $\Delta$ LAI-induced increase in ET is $4.0 \pm 0.8 \mathrm{~mm} \mathrm{yr}^{-1}$ decade $^{-1}$ (Figs. 1c, 5a, and 6).

As for the spatial pattern of soil moisture change, two distinct situations can take place following the regional wetness or dryness (Fig. 7a). The key lies in the spatial distribution of $\Delta P$ (Findell et al. 2011; Spracklen et al. 2012; Swann et al. 2012; Devaraju et al. 2015). Over forest regions, usually relatively wet and with greater moisture recycling, because the forest acts as an efficient biotic water pump of atmospheric moisture (Sheil and Murdiyarso 2009; Spracklen et al. 2012; Makarieva et al. 2013), the enhanced atmospheric moisture caused by $\Delta \mathrm{ET}$ turns out to increase regional $P$. This is evident over forested regions such as Amazonia, the Congo basin, boreal forest regions, and Southeast Asia including southern China (Fig. 1e). The increase of $P$ is even larger than that of ET over these regions, which resupplies soil moisture or increases runoff (Fig. 3b and Fig. S7). Over most nonforest regions, usually relatively dry, there is a significant reduction of SWC (Fig. 7a) despite there being no significant changes in runoff (Fig. 7b) and $P-E$ (Fig. S7). Considering that the LAI-induced disequilibrium between $P$ and ET is reflected by an adjustment of runoff in wet regions/periods, and of soil moisture in dry regions/periods (Fig. 7c), the significant decrease of SWC in dry regions should be a result of increasing ET because soil moisture integrates cumulative ET changes over periods from weeks to months (Figs. 7 and 8). However, we should also note that the precipitation biases in the model (Fig. S4c) might result in biases in the modeled soil moisture response because the response of soil moisture to LAI change is constrained in different ways at the wettest and driest ends (Meng et al. 2014). In the dry regions where significant reduction of soil moisture was modeled, there are dry biases in the Sahel and northern India, and wet biases in west Asia, the western United States, and the Mediterranean coast (Table S2). Given that the modeled soil moisture is near the wilting point in dry areas, the dry bias indicates that the model has underestimated the moisture response in the Sahel and northern India, while the wet bias indicates an overestimation in west Asia, the western United States, and the Mediterranean coast.

\section{d. Importance of $\triangle L A I$ to changes in observed ET, $P$, and $S W C$ for the last 30 years}

The constraint of satellite-observed LAI improves the capacity of the model to reproduce the observed variations of land ET and $P$ for the last 30 years. The modeled land ET in the standard AMIP simulation (AMIP_STD) already reproduces some of the observed interannual variations of land ET derived from several data products 

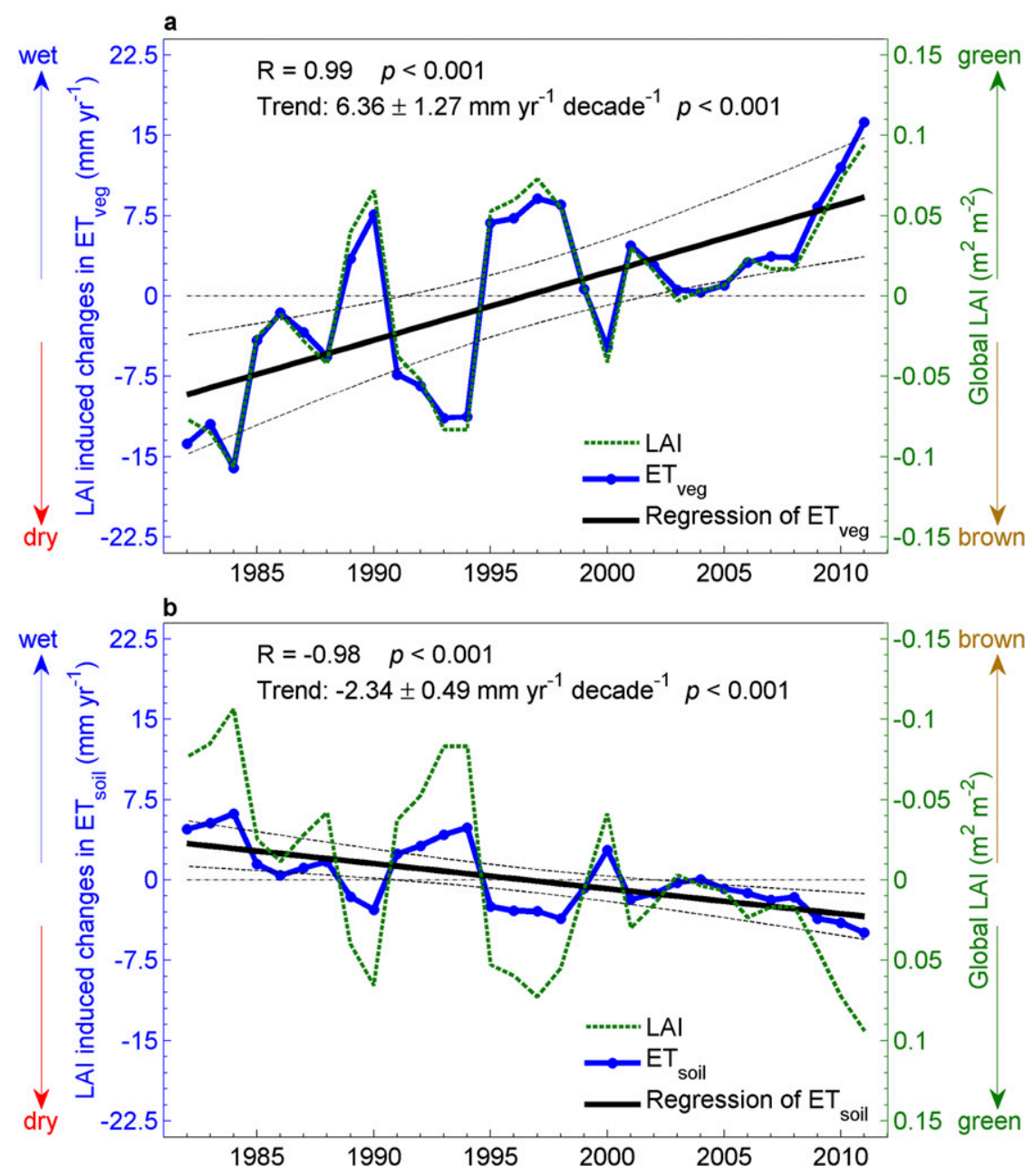

FIG. 9. Temporal variation of global average LAI (green line) and LAI-induced variation in ET (blue line) from (a) vegetation and (b) soil. LAI-induced variations of ET from vegetation and soil are isolated from AMIP_LAI - AMIP_STD. The black line is the least squares regression of ET against time. Inserted numbers show the correlation $R$ between ET and LAI, and the trend of LAI-induced variation of ET.

(Table S1), for example, FLUXNET-MTE ET $(R=$ $0.39, p<0.05)$, GRACE-MTE ET $(R=0.76, p<0.01)$, $\operatorname{MPM} \operatorname{ET}(R=0.46, p<0.01), \mathrm{P}-\mathrm{LSH} \operatorname{ET}(R=0.62, p<$ $0.01)$, and PML ET $(R=0.54, p<0.01)$. Constrained with the satellite-observed LAI in AMIP_LAI, the interannual correlation between modeled ET and the same data products increases by an average of $0.23 \pm$ 0.07 (Table S3). In terms of precipitation, the observed interannual variation over land is well reproduced in AMIP_STD $(R=0.85$ for GPCC $P$ and $R=0.77$ for CRU $P$, both with $p<0.01$ ), and the skill is a little stronger when the variation of LAI is included in AMIP_LAI (Table S4).

In AMIP_STD, the observed change in SST for 19822011 has significantly increased land ET by $3.5 \mathrm{~mm} \mathrm{yr}^{-1}$ decade $^{-1}(p<0.01)$ and the ocean-land water transport by $962 \mathrm{~km}^{3} \mathrm{yr}^{-1}$ decade $^{-1}(p<0.1)$, contributing to an increase of land $P$ by $9.9 \mathrm{~mm} \mathrm{yr}^{-1}$ decade $^{-1}(p<0.01$; Table 1). Yet the magnitude is obviously lower than the observed trend in land $P$ for both CRU and GPCC (black bar versus blue bars, Fig. 10). Compared to AMIP_STD, because of the inclusion of a $\triangle$ LAI-induced increase of $P\left(4.0 \mathrm{~mm} \mathrm{yr}^{-1}\right.$ decade $^{-1}, p<0.01$; Table 1$)$, the trend of land $P$ in AMIP_LAI matches the observed trend of land $P$ from GPCC and CRU products (green bar versus blue bars, Fig. 10).

To further evaluate the importance of $\Delta \mathrm{LAI}$-induced changes in the terrestrial water cycle, we compare the signal of enhanced LAI against the interannual variability (IAV) and the trends of observed ET (Figs. 11a,b) and $P$ (Figs. 11c,d) during the past 30 years. The LAI-induced IAV of ET $\left(5.1 \mathrm{~mm} \mathrm{yr}^{-1}\right)$ is of the same magnitude as the 


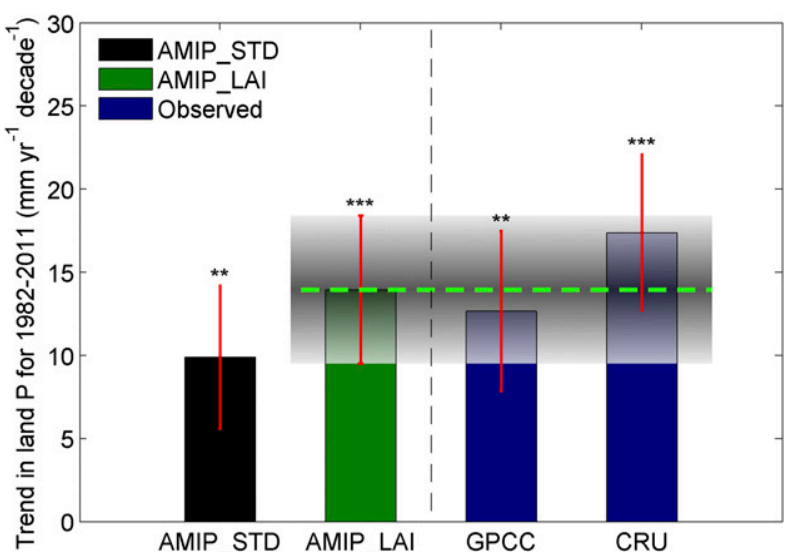

FIG. 10. Trends in land $P$ for $1982-2011$ from the transient experiment (AMIP_STD, AMIP_LAI) and the observations (GPCC, CRU). Error bars show one standard error of the trends. The significance of the trends is shown with asterisks, where *** indicates significance at the $99 \%$ confidence interval, $* *$ indicates significance at the $95 \%$ confidence interval, * indicates significance at the $90 \%$ confidence interval, and n.s. means not significant. The horizontal dashed line is the modeled trend of land $P$ caused by the change of SST and increasing LAI from 1982 to 2011, and the shadow shows one standard error.

observed IAV of land ET over the past 30 years derived from the above data products (Fig. 11a). The modeled trend in land ET as a response to change in LAI alone accounts for $23 \%-92 \%$ (average: $55 \% \pm 25 \%$ ) of the observed trend in land ET during the past 30 years, depending on the ET dataset used as a reference (Fig. 11b). Our results suggest that $\Delta \mathrm{LAI}$, which includes the biogeochemical $\left(\mathrm{CO}_{2}\right.$ fertilization) effect as well as the effects of land-use and land-cover change where it happened over the last 30 years and climate-related mechanisms responsible for LAI changes over time (Piao et al. 2015; Mao et al. 2016; Zhu et al. 2016), has been an important driver of land ET change during the past 30 years.

The IAV of land precipitation $\left(5.5 \mathrm{~mm} \mathrm{yr}^{-1}\right)$ in response to the interannual variation of LAI alone accounts for a fraction $(21 \%)$ of the total IAV in observed land $P$ from GPCC and CRU products (Fig. 11c), the rest being caused by other factors (e.g., SST, climate forcing of greenhouse gases, and aerosols). The $\Delta$ LAI-induced $\Delta P$ accounts for, on average, $28 \% \pm 6 \%$ of the observed trend in land $P$ during the past 30 years estimated from GPCC (32\%) and CRU $(23 \%)$. Although the change in precipitation over land during the past 30 years was primarily caused by other factors such as interannual to decadal modes of climate variability, greenhouse gases, and aerosols, this result suggests that the role of increasing LAI is not negligible.
Last but not least, spatially, there is significant overlap between the $\triangle$ LAI-induced ET trend (Fig. 1c) and the observed ET trend (e.g., Fig. 3b in Zeng et al. 2012; Fig. 6a in Zeng et al. 2014; Fig. 1b in Zhang et al. 2015; Fig. 5a in Zhang et al. 2016). For example, $\Delta$ LAI significantly increased ET over Europe, the boreal Asia, eastern America, Amazonia, the Sahel, southern India, eastern China, and northern Australia (Fig. 1c), where almost all the ET products show positive ET trend during the past 30 years (e.g., Zeng et al. 2012, 2014; Zhang et al. 2015, 2016). The $\Delta$ LAI did not change and/ or even decreased ET in the western United States, southern South America, central Africa, and western Asia, where some ET products did show a negative ET trend over these regions (e.g., Zeng et al. 2012, 2014; Zhang et al. 2015, 2016). Thus, the spatial coherence between the $\Delta$ LAI-induced ET trend and the observed ET trend provides further evidence of the importance of $\Delta$ LAI to the terrestrial water cycle change during the last 30 years.

\section{Discussion}

\section{a. A conceptual analysis on the $\Delta L A I$-induced relative change in transpiration}

A condition to accurately simulate the impact of greening on the terrestrial water cycle is to well simulate the response of ET to the LAI change (Zeng et al. 2016). Here we provide a conceptual analysis on the $\Delta$ LAI-induced relative change in transpiration for a comparison of model simulations. In general, plant transpiration $\left(E_{\mathrm{veg}}\right)$ is an integral over the individual leaf area in the canopy, as in

$$
E_{\mathrm{veg}}=\int E_{i} d L,
$$

where $L$ is LAI and $E_{i}$ is the transpiration from small leaf element $d L$. It can be approximated as

$$
E_{\mathrm{veg}}=\alpha \bar{E} L,
$$

where $\bar{E}$ is mean transpiration rate per leaf area, and $\alpha$ is a function varying with $L$. Because 1) $\alpha$ declines markedly with increasing $L$ when $L$ is low and 2) $\alpha$ is a gradual saturating functional response linking low $L$ and high $L$ (Schulze et al. 1994), we assume that $\alpha$ can be expressed as a negative exponential function of $L$, that is, $\alpha=k_{1}+k_{2} e^{-L}$, where $k_{1}$ and $k_{2}$ are parameters. Assuming that $\alpha$ equals 1 for low $L(L=0)$ and that $\alpha$ is around $1 / 3$ for high $L(L=10$; Schulze et al. 1994), we therefore estimate $k_{1}=1 / 3$ and $k_{2}=2 / 3$. Furthermore, the $\Delta \mathrm{LAI}$-induced relative change in 

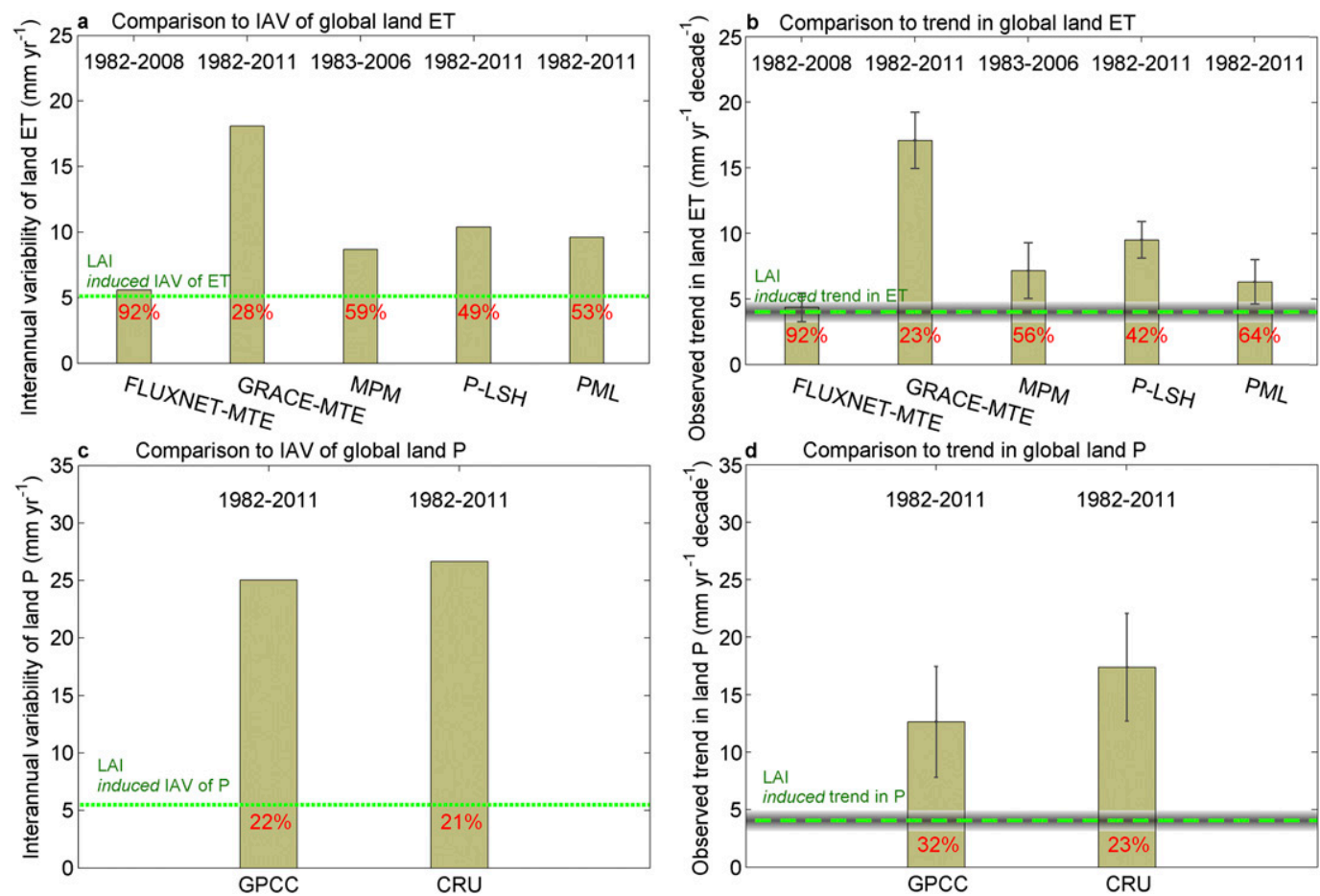

FIG. 11. Comparisons of LAI-induced changes of ET and $P$ with IAV and trend of observed ET and $P$, respectively. IAV from the observation-based estimates of (a) global land ET and (c) global land $P$. The trend from the observation-based estimates of (b) global land ET and (d) global land $P$. The horizontal dashed lines in (a) -(d) are the LAI-induced IAV of ET, trend of ET, IAV of $P$, and trend of $P$, respectively. The shadow shows the standard error of the trends. The numbers show the period for each observation-based estimate.

transpiration can be decomposed into the changes in $\alpha$, $\bar{E}$, and $L$, as in

$$
\frac{d E_{\mathrm{veg}}}{E_{\mathrm{veg}}}=\frac{d \alpha}{\alpha}+\frac{d \bar{E}}{\bar{E}}+\frac{d L}{L} .
$$

The satellite-observed increase of $L$ is around $8 \%$ during the period 1982-2011 (Zhu et al. 2013) $(d L / L=8 \%)$. When $L$ increases by $8 \%$ from 1.51 to $1.63 \mathrm{~m}^{2} \mathrm{~m}^{-2}, \alpha$ decreases from 0.48 to 0.46 . Thus, $d \alpha / \alpha=-3 \%$. Because our goal is to quantify the LAIinduced change in the water cycle, the $\mathrm{CO}_{2}$ scenario in AMIP_LAI is the same as that in AMIP_STD. The term $d \bar{E} / \bar{E}$ should therefore be a constant $(d \bar{E} / \bar{E} \approx 0)$. Therefore, the relative change in transpiration resulting from the increasing LAI should be $5 \%$. This is a simplified, global average estimate, which differs from the transpiration response of an individual tree to increasing LAI. The latter is elastic, controlled by the ecological behavior and climatological condition. In spite of this, such an observation-based estimate provides criteria for global model simulations.

The modeled increase of plant transpiration caused by the observed increase of $L$, globally, is also $5 \%$ in the numerical experiments by IPSLCM GCM, which is consistent with the conceptual analysis.

\section{$b$. The effect of rising atmospheric $\mathrm{CO}_{2}$ on the climate feedback of Earth greening}

In this paper, we focus on the impacts of Earth greening on the terrestrial water cycle over the past three decades. Yet the impact may be buffered by the enhancement of water-use efficiency resulting from increasing atmospheric $\mathrm{CO}_{2}$ during this period. We used four equilibrium simulations (CTL, TRN, TLI, and REC) to investigate the effect of rising atmospheric $\mathrm{CO}_{2}$ on the LAI-induced change in the terrestrial water cycle. The comparison between TLI and CTL represents the model response to increasing $\mathrm{LAI}$ when $\mathrm{CO}_{2}$ was held at the same level as in 1982, and that between REC and TRN shows the response when $\mathrm{CO}_{2}$ was held at the same level as in 2011. We found the equilibrium response of the terrestrial water cycle to increasing $\mathrm{LAI}$ and $\mathrm{CO}_{2}$ estimated from REC - CTL (Figs. S12 and S13) to be similar to that when only LAI increases, that is, as estimated from REC - TRN (Figs. 3 and S9). This indicates that rising $\mathrm{CO}_{2}$ does not change the impacts of global LAI change on the terrestrial water cycle. In fact, rising 


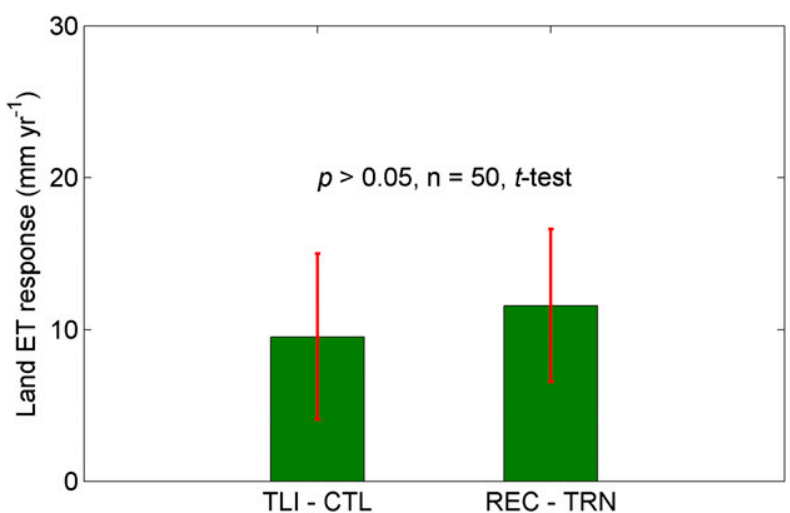

FIG. 12. Response of land ET to increasing LAI in the simulations of low atmospheric $\mathrm{CO}_{2}$ concentration (set in 1982; TLI CTL) and the simulations of high atmospheric $\mathrm{CO}_{2}$ concentration (set in 2011; REC - TRN). Error bars show one standard variation of annual land ET within each 50-yr-long simulation. According to a $t$ test, there is no significant difference between TLI - CTL and REC - TRN $(p>0.05, n=50)$.

$\mathrm{CO}_{2}$ not only decreases transpiration by increasing wateruse efficiency through the physiological effect, but also increases evapotranspiration via the radiative effect over land. A comparison of climate between REC - TRN and TLI - CTL reveals that the effects of rising $\mathrm{CO}_{2}$ do not significantly change the sensitivity of ET to LAI during the past 30 years (Fig. 12), and the nonsignificant difference dominates over land pixels ( $t$ test, $p>0.05, n=50$ ). The results indicate that the reduction of ET caused by the physiological effect of rising $\mathrm{CO}_{2}$ is mostly cancelled out by the increase of ET resulting from the radiative effect of rising $\mathrm{CO}_{2}$ over land, which is consistent with the findings in previous studies (e.g., Betts et al. 1997; Bounoua et al. 1999; Cao et al. 2010). However, because the effects of rising $\mathrm{CO}_{2}$ are nonlinear, studies extrapolating these effects in the future should be cautious. Besides, the impact may also be buffered by changing aerosols, which has not been quantified in this study and is worthy of continuing efforts.

\section{c. Implications for predicting the terrestrial water cycle}

The terrestrial water cycle has intensified in response to global warming over the last 30 years (Huntington 2006; Jung et al. 2010; Vinukollu et al. 2011; Zeng et al. 2014). We find that the observed increase of LAI was a significant contribution to the positive trend of global land ET, which also feeds back on climate. Surprisingly, most of the global ET observation-based products indicate a decline of global ET trend after 1998 (Jung et al. 2010; Vinukollu et al. 2011), mainly over semiarid regions (Jung et al. 2010; Zeng et al. 2014). Jung et al. (2010) suggested that the decline of global land ET trend was a result of soil moisture limitation in semiarid regions.
Although soil moisture is mainly controlled by precipitation in dry regions, our simulations indicate that the greeninginduced soil moisture reduction [the greening itself possibly caused by precipitation as well as other factors such as rising $\mathrm{CO}_{2}$ and land-use change (Piao et al. 2015; Mao et al. 2016; Zhu et al. 2016; Figs. 7a and 8)] is superimposed on the interannual variability of precipitation and contributes to a decreasing soil moisture trend in semiarid regions.

Because the dynamics of LAI play a pivotal role in regulating the water cycle, it is important that this variable is simulated correctly in land surface models. The capacity of Earth system models (ESMs) to simulate the spatiotemporal variation of LAI partly determines the reliability of these models in predicting terrestrial water cycle changes. We compared the observed global land LAI (Zhu et al. 2013) with the simulated one for 1982-2005 from the coupled runs of 27 ESMs in CMIP5 (Table S5; Taylor et al. 2012). Their capacity to simulate LAI dynamics spans a wide range (Figs. S14-S16). Most ESMs overestimate the magnitude of LAI (Fig. S17), and underestimate its IAV (Fig. S18) and trend (Fig. S19). Furthermore, biases of the LAI trend in the ESMs give rise to biases of their ET trends. So far, there are inherent biases in the sensitivity of ET to LAI in the CMIP5 ESMs (Zeng et al. 2016) that are necessary to be calibrated for a better simulation of land-climate interaction. On the one hand, we call for more studies to identify the factors driving the sensitivity biases in different models and/or the same model but with different resolutions and physical schemes. On the other hand, if the sensitivity has been calibrated using the Earth's sensitivity of land ET to land LAI (Zeng et al. 2016), we estimate that biases of LAI in the CMIP5 models can be translated into biases of ET trend ranging from an underestimation of $3.7 \mathrm{~mm} \mathrm{yr}^{-1}$ decade $^{-1}$ to an overestimation of $4.8 \mathrm{~mm} \mathrm{yr}^{-1}$ decade $^{-1}$ (Fig. S20). Thus, a more accurate representation of LAI dynamics and the ET sensitivity to LAI change in ESMs is needed if we are to improve the simulation of the terrestrial water cycle and hence the prediction of how water resources will respond to climate change. Such improvement is also indispensable if we are to develop effective strategies for mitigation of climate change impact through land-use changes. One way to ameliorate models is to correct the initialization, distribution, and parameterization of vegetation phenology in land surface models to improve the LAI dynamics (Anav et al. 2013), with the ultimate objective of reducing uncertainties on vegetation feedbacks in climate projections.

\section{Conclusions}

To the best of our knowledge, this is the first quantitative estimate of how the terrestrial water cycle has 
been influenced by the satellite-observed widespread increase of leaf area over the land surface. We found an unexpected contribution of increasing LAI to the observed hydrological intensification. Increasing LAI intensifies moisture recycling through a coincident increase of evapotranspiration and precipitation over wet regions, but over dry regions, increasing LAI causes a significant decrease of soil moisture. This implies that it is essential to accurately represent LAI and its feedbacks in Earth system models for simulations and predictions of how the terrestrial water cycle responds to climate change.

This study has increased our understanding of how vegetation change produces change in the terrestrial water cycle, but as with all studies, uncertainties remain. First, the LAI product used to constrain the IPSLCM GCM has uncertainties arising from the regression algorithm, the saturation effect in NDVI, lack of onboard calibration, and the orbital loss problem of AVHRR sensors (Tucker et al. 2005; Zhu et al. 2013). Thus, systematic errors in the satellite LAI product can cause a mismatch between modeled changes in terrestrial water fluxes and the observations. Nevertheless, continuing efforts are being made to produce more accurate and consistent LAI time series and reduce systematic uncertainties and their variation in time (Pinzon and Tucker 2014; Zhu et al. 2016). Second, the LAI-induced changes in the terrestrial water cycle may in turn impact vegetation activity, particularly through drought events, which again affects the terrestrial water cycle. This indirect effect was not considered in this study, as we have aimed for the quantification of the direct feedback of vegetation on climate. This comparative experiment was performed to estimate the impact of the observed LAI change on the terrestrial water cycle over the past three decades. This estimate has excluded the uncertainty caused by initial conditions by using a large IC-ensemble. However, one caveat of the estimate is the uncertainty resulting from the limitation in our knowledge of and abilities to represent the Earth system, including parameterizations of cumulus convection, turbulence, radiation, cloud microphysics, and land surface processes. Among the most important caveats are the model precipitation biases, as it is possible to induce biases of the modeled soil moisture response. It is essential to improve the accuracy of representing the Earth system, particularly the precipitation processes, in the models. Otherwise, to reduce uncertainty, it is highly desirable to have multimodel ensembles using ESMs with different parameterization schemes.

Acknowledgments. We wish to thank two anonymous reviewers for constructive comments that helped to strengthen this analysis. This study was supported by the National Natural Science Foundation of China (41125004), National Youth Top-notch Talent Support Program in China, the 111 Project (B14001), and the ANR China-Trend-Stream project. We thank the National Supercomputer Center in Tianjin (NSCC-TJ) and the National Computer Center IDRIS/CNRS in France for providing computing resources. J. Mao and X. Shi are partially supported by the Reducing Uncertainties in Biogeochemical Interactions through Synthesis and Computing Scientific Focus Area (RUBISCO SFA), which is sponsored by the Regional and Global Climate Modeling (RGCM) Program in the Climate and Environmental Sciences Division (CESD) of the Biological and Environmental Research (BER) Program in the U.S. Department of Energy Office of Science. Oak Ridge National Laboratory is managed by UT-BATTELLE for DOE under Contract DE-AC05-00OR22725.

\section{REFERENCES}

Anav, A., G. Murray-Tortarolo, P. Friedlingstein, S. Sitch, S. L. Piao, and Z. C. Zhu, 2013: Evaluation of land surface models in reproducing satellite derived leaf area index over the highlatitude Northern Hemisphere. Part II: Earth System Models. Remote Sens., 5, 3637-3661, https://doi.org/10.3390/rs5083637.

Betts, R. A., P. M. Cox, S. E. Lee, and F. I. Woodward, 1997: Contrasting physiological and structural vegetation feedbacks in climate change simulations. Nature, 387, 796-799, https:// doi.org/10.1038/42924.

Bisselink, B., and A. J. Dolman, 2009: Recycling of moisture in Europe: Contribution of evaporation to variability in very wet and dry years. Hydrol. Earth Syst. Sci., 13, 1685-1697, https:// doi.org/10.5194/hess-13-1685-2009.

Bosch, J. M., and J. D. Hewlett, 1982: A review of catchment experiments to determine the effect of vegetation changes on water yield and evapotranspiration. J. Hydrol., 55, 3-23, https://doi.org/10.1016/0022-1694(82)90117-2.

Bounoua, L., and Coauthors, 1999: Interactions between vegetation and climate: Radiative and physiological effects of doubled atmospheric $\mathrm{CO}_{2}$. J. Climate, 12, 309-324, https://doi.org/ 10.1175/1520-0442(1999)012<0309:IBVACR>2.0.CO;2.

— , G. J. Collatz, S. O. Los, P. J. Sellers, D. A. Dazlich, C. J. Tucker, and D. A. Randall, 2000: Sensitivity of climate to changes in NDVI. J. Climate, 13, 2277-2292, https://doi.org/10.1175/ 1520-0442(2000)013<2277:SOCTCI >2.0.CO;2.

Brubaker, K. L., D. Entekhabi, and P. S. Eagleson, 1993: Estimation of continental precipitation recycling. J. Climate, 6, 1077-1089, https://doi.org/10.1175/1520-0442(1993)006<1077: EOCPR $>2.0 . \mathrm{CO} ; 2$.

Cao, L., G. Bala, K. Caldeira, R. Nemani, and G. Ban-Weiss, 2010: Importance of carbon dioxide physiological forcing to future climate change. Proc. Natl. Acad. Sci. USA, 107, 9513-9518, https://doi.org/10.1073/pnas.0913000107.

Dai, A., K. E. Trenberth, and T. Qian, 2004: A global dataset of Palmer Drought Severity Index for 1870-2002: Relationship with soil moisture and effects of surface warming. J. Hydrometeor., $\mathbf{5}$, 1117-1130, https://doi.org/10.1175/JHM-386.1.

Devaraju, N., G. Bala, and A. Modak, 2015: Effects of large-scale deforestation on precipitation in the monsoon regions: Remote 
versus local effects. Proc. Natl. Acad. Sci. USA, 112, 3257-3262, https://doi.org/10.1073/pnas.1423439112.

Dirmeyer, P. A., C. A. Schlosser, and K. L. Brubaker, 2009: Precipitation, recycling, and land memory: An integrated analysis. J. Hydrometeor., 10, 278-288, https://doi.org/10.1175/ 2008JHM1016.1.

Dufresne, J.-L., and Coauthors, 2013: Climate change projections using the IPSL-CM5 Earth System Model: From CMIP3 to CMIP5. Climate Dyn., 40, 2123-2165, https://doi.org/10.1007/ s00382-012-1636-1.

Ellison, D., M. N. Futter, and K. Bishop, 2012: On the forest coverwater yield debate: From demand- to supply-side thinking. Global Change Biol., 18, 806-820, https://doi.org/10.1111/ j.1365-2486.2011.02589.x.

Fang, J. Y., and Coauthors, 2014: Evidence for environmentally enhanced forest growth. Proc. Natl. Acad. Sci. USA, 111, 9527-9532, https://doi.org/10.1073/pnas.1402333111.

Farley, K. A., E. G. Jobbágy, and R. B. Jackson, 2005: Effects of afforestation on water yield: A global synthesis with implications for policy. Global Change Biol., 11, 1565-1576, https:// doi.org/10.1111/j.1365-2486.2005.01011.x

Findell, K. L., P. Gentine, B. R. Lintner, and C. Kerr, 2011: Probability of afternoon precipitation in eastern United States and Mexico enhanced by high evaporation. Nat. Geosci., $\mathbf{4}$, 434-439, https://doi.org/10.1038/ngeo1174.

Forkel, M., N. Carvalhais, C. Rödenbeck, R. Keeling, M. Heimann, K. Thonicke, S. Zaehle, and M. Reichstein, 2016: Enhanced seasonal $\mathrm{CO}_{2}$ exchange caused by amplified plant productivity in northern ecosystems. Science, 351, 696-699, https://doi.org/ 10.1126/science.aac4971.

Goulden, M. L., and R. C. Bales, 2014: Mountain runoff vulnerability to increased evapotranspiration with vegetation expansion. Proc. Natl. Acad. Sci. USA, 111, 14071-14 075, https:// doi.org/10.1073/pnas.1319316111.

Graven, H. D., and Coauthors, 2013: Enhanced seasonal exchange of $\mathrm{CO}_{2}$ by northern ecosystems since 1960 . Science, 341, 10851089, https://doi.org/10.1126/science.1239207.

Hales, K., J. D. Neelin, and N. Zeng, 2004: Sensitivity of tropical land climate to leaf area index: Role of surface conductance versus albedo. J. Climate, 17, 1459-1473, https://doi.org/ 10.1175/1520-0442(2004)017<1459:SOTLCT $>2.0$.CO;2.

Harris, I., P. D. Jones, T. J. Osborn, and D. H. Lister, 2014: Updated high-resolution grids of monthly climatic observations-The CRU TS3.10 dataset. Int. J. Climatol., 34, 623-642, https://doi.org/ $10.1002 /$ joc. 3711.

He, J., and B. J. Soden, 2016: The impact of SST biases on projections of anthropogenic climate change: A greater role for atmosphere-only models? Geophys. Res. Lett., 43, 7745-7750, https://doi.org/10.1002/2016GL069803.

Hourdin, F., and Coauthors, 2006: The LMDZ4 general circulation model: Climate performance and sensitivity to parametrized physics with emphasis on tropical convection. Climate Dyn., 27, 787-813, https://doi.org/10.1007/ s00382-006-0158-0.

Huntington, T. G., 2006: Evidence for intensification of the global water cycle: Review and synthesis. J. Hydrol., 319, 83-95, https://doi.org/10.1016/j.jhydrol.2005.07.003.

IPCC, 2013: Climate Change 2013: The Physical Science Basis. Cambridge University Press, 1535 pp., https://doi.org/10.1017/ CBO9781107415324.

Jackson, R. B., and Coauthors, 2005: Trading water for carbon with biological carbon sequestration. Science, 310, 1944-1947, https://doi.org/10.1126/science.1119282.
Jasechko, S., Z. D. Sharp, J. J. Gibson, S. J. Birks, Y. Yi, and P. J. Fawcett, 2013: Terrestrial water fluxes dominated by transpiration. Nature, 496, 347-350, https://doi.org/10.1038/nature11983.

Jung, M., and Coauthors, 2010: Recent decline in the global land evapotranspiration trend due to limited moisture supply. $\mathrm{Na}$ ture, 467, 951-954, https://doi.org/10.1038/nature09396.

Kay, J. E., and Coauthors, 2015: The Community Earth System Model (CESM) large ensemble project: A community resource for studying climate change in the presence of internal climate variability. Bull. Amer. Meteor. Soc., 96, 1333-1349, https://doi.org/10.1175/BAMS-D-13-00255.1.

Kosaka, Y., and S.-P. Xie, 2013: Recent global-warming hiatus tied to equatorial Pacific surface cooling. Nature, 501, 403-407, https://doi.org/10.1038/nature12534.

Krinner, G., and Coauthors, 2005: A dynamic global vegetation model for studies of the coupled atmosphere-biosphere system. Global Biogeochem. Cycles, 19, GB1015, https://doi.org/ 10.1029/2003GB002199.

Li, Z.-X., 1999: Ensemble atmospheric GCM simulation of climate interannual variability from 1979 to 1994 . J. Climate, $\mathbf{1 2}$, 986-1001, https://doi.org/10.1175/1520-0442(1999)012<0986: EAGSOC $>2.0 . \mathrm{CO} ; 2$.

Lorenz, E. N., 1963: Deterministic nonperiodic flow. J. Atmos. Sci., 20, 130-141, https://doi.org/10.1175/1520-0469(1963)020<0130: $\mathrm{DNF}>2.0 . \mathrm{CO} ; 2$.

Mahowald, N., F. Lo, Y. Zheng, L. Harrison, C. Funk, D. Lombardozzi, and C. Goodale, 2016: Projections of leaf area index in Earth system models. Earth Syst. Dyn., 7, 211229, https://doi.org/10.5194/esd-7-211-2016.

Makarieva, A. M., V. G. Gorshkov, and B.-L. Li, 2013: Revisiting forest impact on atmospheric water vapor transport and precipitation. Theor. Appl. Climatol., 111, 79-96, https://doi.org/ 10.1007/s00704-012-0643-9.

Mao, J., and Coauthors, 2016: Human-induced greening of the northern extratropical land surface. Nat. Climate Change, $\mathbf{6}$, 959-963, https://doi.org/10.1038/nclimate3056.

McMahon, S. M., G. G. Parker, and D. R. Miller, 2010: Evidence for a recent increase in forest growth. Proc. Natl. Acad. Sci. USA, 107, 3611-3615, https://doi.org/10.1073/ pnas.0912376107.

Meng, X. H., J. P. Evans, and M. F. McCabe, 2014: The impact of observed vegetation changes on land-atmosphere feedbacks during drought. J. Hydrometeor., 15, 759-776, https://doi.org/ 10.1175/JHM-D-13-0130.1.

Mueller, B., and S. I. Seneviratne, 2014: Systematic land climate and evapotranspiration biases in CMIP5 simulations. Geophys. Res. Lett., 41, 128-134, https://doi.org/10.1002/ 2013 GL058055.

Pfeifer, M., V. Lefebvre, A. Gonsamo, P. K. E. Pellikka, R. Marchant, D. Denu, and P. J. Platts, 2014: Validating and linking the GIMMS leaf area index (LAI3g) with environmental controls in tropical Africa. Remote Sens., 6, 1973-1990, https://doi.org/10.3390/rs6031973.

Piao, S. L., and Coauthors, 2015: Detection and attribution of vegetation greening trend in China over the last 30 years. Global Change Biol., 21, 1601-1609, https://doi.org/10.1111/ gcb.12795.

Pinzon, J. E., and C. J. Tucker, 2014: A non-stationary 1981-2012 AVHRR NDVI $3 \mathrm{~g}$ time series. Remote Sens., 6, 6929-6960, https://doi.org/10.3390/rs6086929.

Rebel, K. T., R. A. M. de Jeu, P. Ciais, N. Viovy, S. L. Piao, G. Kiely, and A. J. Dolman, 2012: A global analysis of soil moisture derived from satellite observations and a land 
surface model. Hydrol. Earth Syst. Sci., 16, 833-847, https:// doi.org/10.5194/hess-16-833-2012.

Schneider, U., A. Becker, P. Finger, A. Meyer-Christoffer, B. Rudolf, and M. Ziese, 2011: GPCC full data reanalysis version 6.0 at $0.5^{\circ}$ : Monthly land-surface precipitation from rain-gauges built on GTS-based and historic data. Global Precipitation Climatology Centre, accessed 20 May 2014, https://doi.org/10.5676/DWD_GPCC/FD_M_V6_050.

Schulze, E. D., F. M. Kelliher, C. Korner, J. Lloyd, and R. Leuning, 1994: Relationships among maximum stomatal conductance, ecosystem surface conductance, carbon assimilation rate, and plant nitrogen Nutrition: A global ecology scaling exercise. Annu. Rev. Ecol. Syst., 25, 629-660, https://doi.org/10.1146/ annurev.es.25.110194.003213.

Seneviratne, S. I., 2012: Climate science: Historical drought trends revisited. Nature, 491, 338-339, https://doi.org/10.1038/ 491338a.

Sheil, D., and D. Murdiyarso, 2009: How forests attract rain: An examination of a new hypothesis. BioScience, 59, 341-347, https://doi.org/10.1525/bio.2009.59.4.12.

Shukla, J., and Y. Mintz, 1982: Influence of land-surface evapotranspiration on the Earth's climate. Science, 215, 1498-1501, https://doi.org/10.1126/science.215.4539.1498.

Sitch, S., and Coauthors, 2015: Recent trends and drivers of regional sources and sinks of carbon dioxide. Biogeosciences, $\mathbf{1 2}$, 653-679, https://doi.org/10.5194/bg-12-653-2015.

Spracklen, D. V., S. R. Arnold, and C. M. Taylor, 2012: Observations of increased tropical rainfall preceded by air passage over forests. Nature, 489, 282-285, https://doi.org/10.1038/ nature11390.

Sriver, R. L., C. E. Forest, and K. Keller, 2015: Effects of initial conditions uncertainty on regional climate variability: An analysis using a low-resolution CESM ensemble. Geophys. Res. Lett., 42 , 5468-5476, https://doi.org/10.1002/2015GL064546.

Swann, A. L. S., I. Y. Fung, and J. C. H. Chiang, 2012: Mid-latitude afforestation shifts general circulation and tropical precipitation. Proc. Natl. Acad. Sci. USA, 109, 712-716, https:// doi.org/10.1073/pnas.1116706108.

Taylor, K. E., R. J. Stouffer, and G. A. Meehl, 2012: An overview of CMIP5 and the experiment design. Bull. Amer. Meteor. Soc., 93, 485-498, https://doi.org/10.1175/BAMS-D-11-00094.1.

Traore, A. K., and Coauthors, 2014: Evaluation of the ORCHIDEE ecosystem model over Africa against 25 years of satellite-based water and carbon measurements. J. Geophys. Res. Biogeosci., 119, 1554-1575, https://doi.org/10.1002/ 2014JG002638.

Trenberth, K. E., 1999: Atmospheric moisture recycling: Role of advection and local evaporation. J. Climate, 12, 1368-1381, https:// doi.org/10.1175/1520-0442(1999)012<1368:AMRROA > 2.0.CO;2.

Tucker, C. J., J. E. Pinzon, M. E. Brown, D. A. Slayback, E. W. Pak, R. Mahoney, E. F. Vermote, and N. El Saleous, 2005: An extended AVHRR 8-km NDVI dataset compatible with MODIS and SPOT vegetation NDVI data. Int. J. Remote Sens., 26, 4485-4498, https://doi.org/10.1080/01431160500168686.

van der Ent, R. J., and H. H. G. Savenije, 2011: Length and time scales of atmospheric moisture recycling. Atmos. Chem. Phys., 11, 1853-1863, https://doi.org/10.5194/acp-11-1853-2011.

,,-- B. Schaefli, and S. C. Steele-Dunne, 2010: Origin and fate of atmospheric moisture over continents. Water Resour. Res., 46, W09525, https://doi.org/10.1029/2010WR009127.

Vinukollu, R. K., R. Meynadier, J. Sheffield, and E. F. Wood, 2011: Multi-model, multi-sensor estimates of global evapotranspiration: Climatology, uncertainties and trends. Hydrol. Processes, 25, 3993-4010, https://doi.org/10.1002/hyp.8393.

$\mathrm{Xu}, \mathrm{L}$., and Coauthors, 2013: Temperature and vegetation seasonality diminishment over northern lands. Nat. Climate Change, 3, 581-586, https://doi.org/10.1038/nclimate1836.

Zeng, Z. Z., S. Piao, X. Lin, G. Yin, S. Peng, P. Ciais, and R. B. Myneni, 2012: Global evapotranspiration over the past three decades: Estimation based on the water balance equation combined with empirical models. Environ. Res. Lett., 7, 014026, https:// doi.org/10.1088/1748-9326/7/1/014026.

, T. Wang, F. Zhou, P. Ciais, J. F. Mao, X. Y. Shi, and S. L. Piao, 2014: A worldwide analysis of spatiotemporal changes in water balance-based evapotranspiration from 1982 to 2009. J. Geophys. Res. Atmos., 119, 1186-1202, https://doi.org/ 10.1002/2013JD020941.

—, Z. Zhu, X. Lian, L. Z. X. Li, A. Chen, X. He, and S. Piao, 2016: Responses of land evapotranspiration to Earth's greening in CMIP5 Earth System Models. Environ. Res. Lett., 11, 104006, https://doi.org/10.1088/1748-9326/11/10/104006.

_ , and Coauthors, 2017: Climate mitigation from vegetation biophysical feedbacks during the past three decades. Nat. Climate Change, 7, 432-436, https://doi.org/10.1038/nclimate3299.

Zhang, K., J. S. Kimball, R. R. Nemani, and S. W. Running, 2010: A continuous satellite-derived global record of land surface evapotranspiration from 1983 to 2006. Water Resour. Res., 46, W09522, https://doi.org/10.1029/2009WR008800.

, Y. Hong, J. J. Gourley, and Z. B. Yu, 2015: Vegetation greening and climate change promote multidecadal rises of global land evapotranspiration. Sci. Rep., 5, 15956, https://doi.org/10.1038/srep15956.

Zhang, Y. Q., and Coauthors, 2016: Multi-decadal trends in global terrestrial evapotranspiration and its components. Sci. Rep., 6, 19124, https://doi.org/10.1038/srep19124.

Zhu, Z. C., and Coauthors, 2013: Global data sets of vegetation leaf area index (LAI) $3 \mathrm{~g}$ and fraction of photosynthetically active radiation (FPAR)3g derived from Global Inventory Modeling and Mapping Studies (GIMMS) normalized difference vegetation index (NDVI3g) for the period 1981 to 2011. Remote Sens., 5, 927-948, https://doi.org/10.3390/rs5020927.

_- and Coauthors, 2016: Greening of the Earth and its drivers. Nat. Climate Change, 6, 791-795, https://doi.org/10.1038/ nclimate 3004. 